${ }^{1}$ Istituto di Ricerche Farmacologiche Mario Negri IRCCS, Bergamo, Italy.

${ }^{2}$ Pediatric and Infant Center for Acute Nephrology, Department of Pediatrics, University of Alabama at Birmingham, Birmingham, $A L, U S A$

${ }^{3}$ Unit of Nephrology and Dialysis, Azienda Socio Sanitaria Territoriale Papa Giovanni XXIII, Bergamo, Italy.

${ }^{4} \mathrm{~L}$. Sacco Department of Biomedical and Clinical Sciences, University of Milan, Milan, Italy.

*e-mail: giuseppe.remuzzi@ marionegri.it

https://doi.org/10.1038/ s41581-018-0054-y

\title{
Maternal and environmental risk factors for neonatal AKI and its long-term consequences
}

Norberto Perico ${ }^{1}$, David Askenazi ${ }^{2}$, Monica Cortinovis ${ }^{1}$ and Giuseppe Remuzzi (1) ${ }^{1,3,4 *}$

Abstract | Acute kidney injury (AKI) is a common and life-threatening complication in critically ill neonates. Gestational risk factors for AKI include premature birth, intrauterine growth restriction and low birthweight, which are associated with poor nephron development and are often the consequence of pre-gestational and gestational factors, such as poor nutritional status. Our understanding of how to best optimize renal development and prevent AKI is in its infancy; however, the identification of pre-gestational and gestational factors that increase the risk of adverse neonatal outcomes and the implementation of interventions, such as improving nutritional status early in pregnancy, have the potential to optimize fetal growth and reduce the risk of preterm birth, thereby improving kidney health. The overall risk of AKI among critically ill and premature neonates is exacerbated postnatally as these infants are often exposed to dehydration, septic shock and potentially nephrotoxic medications. Strategies to improve outcomes - for example, through careful evaluation of nephrotoxic drugs - may reduce the incidence of AKI and its consequences among this population. Management strategies and updated technology that will support neonates with $\mathrm{AKI}$ are greatly needed. Extremely premature infants and those who survive an episode of AKI should be screened for chronic kidney disease until early adulthood. Here, we provide an overview of our current understanding of neonatal $\mathrm{AKI}$, focusing on its relationship to preterm birth and growth restriction. We describe factors that prevent optimal nephrogenesis during pregnancy and provide a framework for future explorations designed to maximize outcomes in this vulnerable population.

Acute kidney injury (AKI) is a life-threatening condition that affects approximately 13 million individuals per year, of whom $85 \%$ live in low-to-middle-income countries ${ }^{1}$. In patients who survive the acute insult, tissue injury is often considered reversible on the basis of the assumption that the surviving tubular epithelial cells will dedifferentiate and proliferate to replace lost cells ${ }^{2-4}$ and/or that tubular progenitor cells will undergo expansion to regenerate necrotic tubule segments ${ }^{5}$. However, the extent of this regenerative process remains ill-defined ${ }^{4}$, and a growing body of evidence indicates that even a mild episode of AKI can substantially increase the risk of developing chronic kidney disease $(\mathrm{CKD})^{6}$, suggesting that kidney regeneration following AKI is limited. The relationship of AKI with CKD is important given the global burden of CKD - a disease that affects approximately $10 \%$ of the general population ${ }^{7}$ and has a risk-multiplier effect on cardiovascular morbidity and mortality ${ }^{8-11}$.

The contribution of fetal events to the development of chronic diseases - such as cardiovascular disease, obesity, hypertension and CKD - is increasingly recognized $^{12-14}$. We now understand that stressful events experienced in utero and during early postnatal life can affect organ development and shape susceptibility to disease through a process known as developmental programming ${ }^{15}$. One of the first observations of developmental programming was made by David Barker, a British physician, who reported high rates of cardiovascular disease among the poorest regions of England and Wales ${ }^{16}$ despite heart disease being considered a condition of affluence. In a study of $>15,000$ adult individuals, he found an unexpected association between low birthweight (LBW) and cardiovascular disease in adults ${ }^{16,17}$. We now understand that LBW (defined as birthweight $<2,500 \mathrm{~g}$ ) and preterm birth (defined as birth before 37 weeks of gestation) are associated with fetal malnourishment, abnormal programming of organs including the kidneys and surrogate markers of low nephron number ${ }^{18,19}$. In humans, nephrogenesis occurs only before birth at term. In infants born at term, nearly 


\section{Key points}

- Even after controlling for multiple potential confounders, acute kidney injury (AKI) is an important determinant of morbidity and mortality in critically ill neonates.

- Prematurity and low birthweight (LBW), which are surrogate indices of reduced nephron endowment, might predispose neonates to AKI.

- Prematurity and LBW are associated with several comorbidities that are themselves risk factors for $\mathrm{AKI}$ in neonates.

- Neonates with critical illness, especially those born prematurely, often receive medications that might increase susceptibility to toxic renal injury and risk of AKI.

- The identification of pre-gestational risk factors and early intervention during pregnancy, especially in the context of maternal nutrition, as well as careful evaluation of infant exposure to nephrotoxic medications, might limit neonatal AKI, although further research is required to optimize renal development in premature infants and support neonates with AKI.

- Neonates who survive AKI might experience long-term renal dysfunction and should be monitored and screened periodically for chronic kidney disease throughout childhood and young-adult life. in the neonatal intensive care unit (NICU), and mortality among these neonates was higher than in those without AKI, even adjusting for potential confounders $(42 \% \text { versus } 5 \%)^{25}$. Other estimates suggest that $4-40 \%$ of extremely low birthweight (ELBW) infants develop AKI. The wide range in the incidence of AKI probably stems from differences in the definition of AKI and the frequency of ascertainment of serum creatinine ( $\mathrm{SCr}$ ) and urine output to define AKI (discussed below) ) $^{27,44,45}$. In one cohort, the mortality of ELBW neonates with AKI was 54\%, more than double that of ELBW infants without $\mathrm{AKI}^{44}$.

These studies and others ${ }^{27,31,46}$ have consistently shown that mortality is higher in infants with AKI than in those without; however, our ability to determine whether AKI is an independent risk factor for mortality after controlling for confounders is limited by sample sizes and study design. In the largest study to date of AKI in neonates, investigators of the Assessment of Worldwide Acute Kidney Epidemiology in Neonate (AWAKEN) study ${ }^{47}$ retrospectively assessed the prevalence of AKI according to gestational age among 2,022 infants admitted to NICUs across 24 sites in 4 countries. Using the modified Kidney Disease: Improving Global Outcomes (KDIGO) definition of AKI for neonates (discussed further below), they identified AKI in 30\% of the cohort but reported differences in the incidence of AKI according to gestational age, with AKI occurring in $45 \%$ of infants born at $\leq 29$ weeks gestation, in $14 \%$ of infants born at 29-36 weeks gestation and in $41 \%$ of infants born at $>36$ weeks gestation. A possible explanation of these findings is that the most premature infants have the highest prevalence of AKI owing to a lack of renal reserve and because they are in the NICU for a long time, where they are exposed to many risk factors for AKI (such as sepsis and nephrotoxic medications). The high prevalence of AKI in the near-term cohort compared with that of neonates born at 29-36 weeks gestation is probably because these infants are very sick. Even after adjusting for multiple confounders, the risk of death among neonates with AKI was more than four times that of neonates without AKI (adjusted OR 4.6, 95\% CI 2.5-8.3; $P<0.0001$ ); AKI was also associated with more days in the NICU (adjusted days 8.8, 95\% $\mathrm{CI}=6.9-11.5 ; P<0.001)$. These data mirror findings from multicentre studies in other critically ill populations. AKI in neonates is strongly associated with poor outcomes and supports the notion that critically ill patients die 'from' AKI and not simply 'with' AKI.

\section{Epidemiology of neonatal AKI}

Our understanding of AKI in critically ill neonates lags behind that of AKI in paediatric and adult populations; however, the past 5 years have seen an intensification of research in this area. Small, single-centre studies in select neonatal groups such as those with very low birthweight $(\mathrm{VLBW})^{24-30}$, IUGR and preterm birth ${ }^{27,31}$, congenital heart disease ${ }^{32-35}$ sepsis $^{36}$, hypoxic injury ${ }^{37-40}$ and infants who receive extracorporeal membrane oxygenation $(\mathrm{ECMO})^{41-43}$ suggest that AKI is common in critically ill neonates. Infants who develop AKI have worse clinical outcomes than those who do not develop AKI. For example, in a cohort of 229 infants with VLBW (defined as $<1,500 \mathrm{~g}$ ), $18 \%$ experienced AKI during their stay

\section{Challenges with the diagnosis of neonatal AKI}

A limitation to epidemiologic studies and those evaluating risk factors for neonatal AKI is the potential for misclassification of AKI, leading to underestimations of AKI incidence. Part of the reason for this misclassification is that no accepted guidelines exist for when measurements of SCr level and urinary output should be obtained. Most studies that have assessed the incidence of AKI in neonates are retrospective, limiting researchers to SCr values available in medical records. Wide differences also exist in the rate of SCr monitoring. For example, the AWAKEN retrospective study ${ }^{47}$ relied on clinical 
record data, which varied widely in measurement frequency. The median number of SCr measurements per baby ranged from 1 to 12 per institution, which correlated with the wide range of AKI rates reported by the centres (3-56\% among institutions). Not surprisingly, there was a significant correlation between the frequency of SCr monitoring and rates of AKI between institutions.

In addition to variations in $\mathrm{SCr}$ and urine output measurement, the methods used to define AKI in neonates are not uniform. SCr level is the most widely used method to define AKI in this population; however, the use of SCr to define AKI in neonates is particularly challenging owing to the obligate cardiovascular and renal adaptations that occur during the transition into the extrauterine environment. Neonatal SCr at birth reflects maternal SCr, but over the following days the neonate establishes its own steady-state SCr level, which is primarily determined by innate kidney function. Kidney function varies greatly by gestational age, as do $\mathrm{SCr}$ trajectories and steady-state SCr levels ${ }^{48}$ (FIG. 1). For example, the SCr of a normal-term neonate will initially reflect maternal SCr and improve over the coming days such that by day $5-7$ of life, their SCr has reached a nadir. In very premature infants, however, SCr will stay high (or perhaps rise to a degree) for weeks, before decreasing, such that their SCr reaches a nadir at 2-4 weeks of age. In this context, it may be normal for an extremely premature infant without AKI to experience a slight rise in SCr level after birth concomitant with the establishment of stable innate kidney function. A study of ELBW infants showed that $89 \%$ of infants born $<26$ weeks gestational age had a rise in $\mathrm{SCr} \geq 0.3 \mathrm{mg} / \mathrm{dl}(26.52 \mu \mathrm{mol} / \mathrm{l})$ over $48 \mathrm{~h}$ during the first week of life ${ }^{27}$. As mentioned above, a healthy neonate with normal kidney function should experience a steady decline in SCr level after birth. The absence of this normal trajectory could signify a substantial injury, as shown in a study of full-term neonates with asphyxia. In this study, infants whose SCr trajectories did not drop as expected (but did not meet the AKI criteria) were compared with those who had a normal SCr trajectory and those with AKI (defined by an increase in SCr $\geq 0.3 \mathrm{mg} / \mathrm{dl}(26.52 \mu \mathrm{mol} / \mathrm{l}))$. Infants whose SCr trajectories did not drop as expected were much more similar to those with AKI than to those with normal SCr trajectories with regard to multiple clinical outcomes (such as ventilator time, vasopressin use and length of hospital stay) and biological outcomes (as determined by urine biomarkers of kidney injury). This finding suggests that, among full-term infants, an abnormal decline in SCr level or any incline in SCr level during the first postnatal week could be indicative of notable kidney injury ${ }^{49}$. As a consequence, diagnosing AKI in neonates on the basis of a small rise in SCr remains challenging, and thus far this issue is unresolved.

Despite these limitations, the most common definitions of neonatal AKI are based on a modification of the KDIGO definition for children and adults, termed the neonatal modified KDIGO criteria ${ }^{31,50}$. This definition relies on an absolute increase in SCr level from a previous trough or a decrease in urine output and defines three levels of AKI. The difference between the neonatal modified AKI KDIGO criteria and the KDIGO criteria for $\mathrm{AKI}$ in children and adults mainly resides in the definition of the reference SCr level as the lowest previous SCr value (TABLE 2). The neonatal modified KDIGO criteria seem to be able to predict clinical outcomes

Table 1 | Analyses of nephron number in newborn babies with low birthweight or born preterm

\begin{tabular}{|c|c|c|c|c|}
\hline Study & Population (n) & $\begin{array}{l}\text { Gestational } \\
\text { age (weeks) }\end{array}$ & Birthweight & $\begin{array}{l}\text { Glomerular number or } \\
\text { radial glomerular counts }\end{array}$ \\
\hline \multirow[t]{2}{*}{$\begin{array}{l}\text { Manalich et al. } \\
(2000)^{18}\end{array}$} & Neonates (18) & $37.0 \pm 1.05$ & Low birthweight & $\begin{array}{l}\text { Glomerular number: } 92.9 \\
\pm 4.85 \times 0.6 \mathrm{~mm}^{2} \text { of renal } \\
\text { cortex }\end{array}$ \\
\hline & Neonates (17) & $38.9 \pm 1.29$ & Normal birthweight & $\begin{array}{l}\text { Glomerular number: } 105.8 \\
\pm 3.91 \times 0.6 \mathrm{~mm}^{2} \text { of renal } \\
\text { cortex }\end{array}$ \\
\hline \multirow[t]{3}{*}{$\begin{array}{l}\text { Rodriguez } \\
\text { et al. }(2004)^{20}\end{array}$} & $\begin{array}{l}\text { Preterm infants } \\
\text { surviving }<40 \text { days (17) }\end{array}$ & $24 \pm 2$ & $\begin{array}{l}\text { Extremely low birthweight: } \\
607 \pm 148 \mathrm{~g}\end{array}$ & $\begin{array}{l}\text { Radial glomerular counts: } \\
5.6 \pm 0.5\end{array}$ \\
\hline & $\begin{array}{l}\text { Preterm infants } \\
\text { surviving } \geq 40 \text { days (12) }\end{array}$ & $27 \pm 3$ & $\begin{array}{l}\text { Extremely low birthweight: } \\
735 \pm 167 \mathrm{~g}\end{array}$ & $\begin{array}{l}\text { Radial glomerular counts: } \\
8.0 \pm 1.2^{c}\end{array}$ \\
\hline & $\begin{array}{l}\text { Newborn babies at } \\
\text { term (10) }\end{array}$ & $40 \pm 1^{d}$ & $3,216 \pm 643 \mathrm{~g}^{\mathrm{d}}$ & $\begin{array}{l}\text { Radial glomerular counts: } \\
10.4 \pm 0.8^{\mathrm{e}}\end{array}$ \\
\hline \multirow[t]{2}{*}{$\begin{array}{l}\text { Faa et al. } \\
(2010)^{249}\end{array}$} & Preterm infants (12) & $25-38$ & $\begin{array}{l}\text { - } 2 \text { of } 12 \text { preterm infants } \\
\text { showed a low birthweight } \\
\text { - } 8 \text { of } 12 \text { preterm infants } \\
\text { showed an extremely low } \\
\text { birthweight, ranging from } \\
665 \mathrm{~g} \text { to } 840 \mathrm{~g}\end{array}$ & $\begin{array}{l}\text { Radial glomerular counts: } \\
5-7\end{array}$ \\
\hline & $\begin{array}{l}\text { Newborn babies at } \\
\text { term (3) }\end{array}$ & $38-41$ & Normal birthweight & $\begin{array}{l}\text { Radial glomerular counts: } \\
7-9\end{array}$ \\
\hline
\end{tabular}

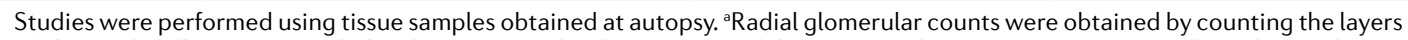
of glomeruli, following a straight line beginning in the deepest zone of the cortex and progressing systematically to the renal capsule, in well-oriented areas. Radial glomerular counts were standardized by counting, in every patient, one renal section in four different locations and averaging them. ${ }^{b} P<0.0001$ versus normal birthweight. ${ }^{c} P<0.001$ versus preterm babies surviving $<40$ days. ${ }^{\mathrm{d}} P<0.05$ versus preterm babies surviving $<40$ days and preterm babies surviving $\geq 40$ days. ${ }^{e} P<0.001$ versus preterm babies surviving $<40$ days and preterm babies surviving $\geq 40$ days. 


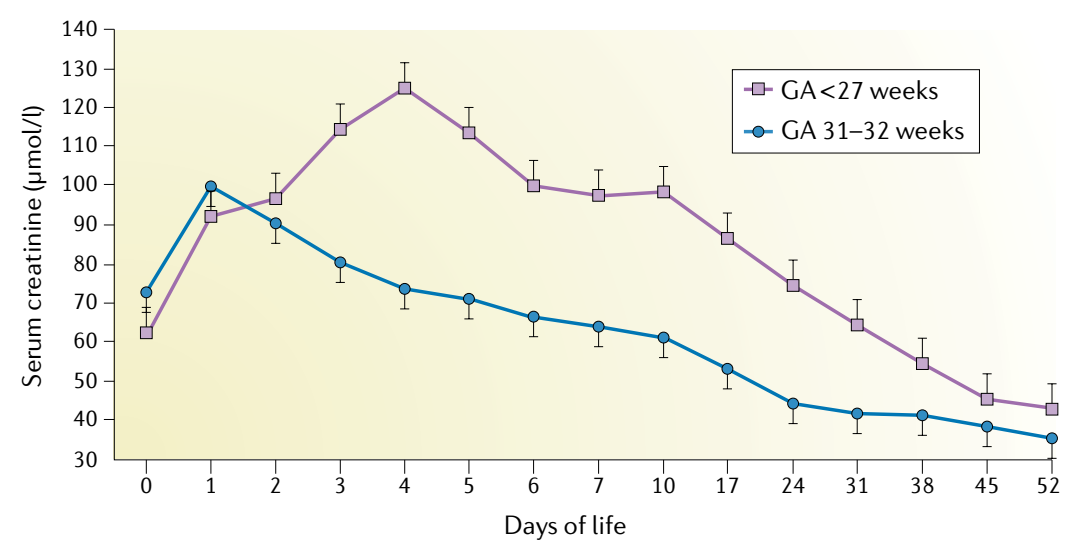

Fig. 1 Changes in serum creatinine concentrations over the first 52 days of life in preterm neonates (gestational age (GA) $<27$ weeks and 31-32 weeks). Figure adapted from REF. ${ }^{65}$, Springer Nature Limited.

independently of potential confounders. In 2013, an expert working group from the US National Institutes of Health (NIH)-sponsored Neonatal AKI Workshop recommended that researchers use the KDIGO definition to define neonatal AKI to enable comparison between studies $^{51}$. However, despite increased use of the modified neonatal KDIGO criteria over the past few years, it must be noted that this definition was adapted from the adult literature ${ }^{52}$ and has not been validated in neonates. The $\mathrm{NIH}$ working group emphasized that these modified criteria or any new definition of neonatal AKI need to be tested against hard end points such as mortality and the development of CKD.

In the absence of this critical step, the field risks using inappropriate definitions to describe the natural history of kidney disease in neonates, which could lead to the failure of intervention studies ${ }^{51}$. Beyond the need to test these criteria in an appropriate population, we suggest that consideration should be given to three important components of the criteria. First, we propose that the use of both percentage SCr rise and absolute SCr rise might add complexity to the neonatal AKI definition without benefit. Perhaps an absolute rise in SCr would be more informative. Second, we note that the use of urinary output as a criterion for neonatal AKI has not been rigorously tested and suggest that studies specifically address the utility of urinary output as a marker of AKI in neonates. Third, our increasing understanding of the impact of fluid overload on outcomes suggests that incorporation of fluid overload into the definition of neonatal AKI could optimize the ability to predict outcomes.

Last, as in adults, kidney injury in neonates will not necessarily lead to an immediate increase in SCr level, with SCr level increasing only once $25-50 \%$ of renal function is $\operatorname{lost}^{48}$. SCr level is therefore not an ideal biomarker for the early detection of AKI in infants, further complicating the diagnosis of AKI in this population. Novel biomarkers to enable earlier identification of AKI include urine neutrophil gelatinase-associated lipocalin (NGAL), cystatin-C, and kidney injury molecule 1 (KIM1; also known as HAVCR1) ${ }^{53-59}$. However, although promising, the diagnosis of $\mathrm{AKI}$ in neonates remains based on a rise in SCr level or changes in urine output.

\section{Risk factors for neonatal AKI}

Preterm birth and LBW are associated with an increased risk of AKI in newborn babies ${ }^{47}$. AKI is particularly common among critically ill neonates in intensive care units (ICUs) and is an important determinant of morbidity and mortality in these infants, many of whom were born with LBW or prematurely ${ }^{31}$. Such infants are more likely than full-term or normal-birthweight infants to have been exposed during intrauterine life to factors that can induce fetal distress, including IUGR, infection, placental insufficiency or maternal medications ${ }^{26,31,60-62}$.

Prematurity and LBW increase the risk of neonatal AKI because impaired nephrogenesis and low nephron endowment ${ }^{26,27,31,60,62,63}$ can result in impaired renal tubular function and low glomerular filtration rate (GFR) and can disrupt renal vasoregulatory processes through ischaemia-reperfusion injury, leading to high renal vascular resistance $27,61,64$. Together, these outcomes increase the vulnerability of the kidney to renal injury after birth ${ }^{65,66}$.

Interestingly, compared with premature infants born to mothers without pre-eclampsia, premature infants born to mothers with pre-eclampsia are protected against $\mathrm{AKI}^{67}$. The mechanism for this protective effect of preeclampsia is unclear but might involve changes in the renal physiology of the neonates (potentially as a result of intermittent renal ischaemia-reperfusion in utero). Alternatively, this observation could reflect the fact that infants born to pre-eclamptic mothers are 'healthy' but delivered early to prevent maternal morbidity, in contrast to infants that are born prematurely because of fetal distress such as chorioamnionitis. Because premature and LBW infants are at increased risk of developing AKI, it is important to understand how pre-gestational and gestational maternal factors affect intrauterine kidney development as well as postnatal risk factors in order to identify preventive and therapeutic interventions.

\section{Pre-gestational risk factors}

Socio-economic factors. Socio-economic disadvantage, whether defined by income, education or occupational status, is associated with an increased risk of giving birth to a preterm ${ }^{68-70}$ or $\mathrm{LBW}^{71}$ baby. Several pathways linking maternal social deprivation and neonatal outcomes have been proposed. For instance, chronic exposure to psychological stress as a consequence of social deprivation might contribute to the use of behavioural coping mechanisms such as alcohol abuse or tobacco consumption, which are known to influence gestational age at birth as well as birthweight ${ }^{72}$. Chronic stress and lack of social support might also affect birth outcomes through neuroendocrine mechanisms, for example, through the release of noradrenaline and cortisol, which have been linked to preterm labour and delivery ${ }^{72}$.

Age. Both young and advanced maternal age are associated with less favourable birth outcomes. A study that pooled data from five low-to-middle-income countries found that, compared with women aged 20-24 years, young mothers ( $\leq 19$ years) had an increased risk of giving birth to an LBW (adjusted OR 1.18, 95\% CI 1.02-1.36) or preterm (adjusted OR 1.26, 95\% CI 1.03-1.53) infant, whereas mothers aged $\geq 35$ years had an increased risk 


\section{Table 2 | Proposed neonatal modified AKI KDIGO classification}

\begin{tabular}{|c|c|c|}
\hline Stage & Serum creatinine & Urine output \\
\hline 0 & No change in serum creatinine or rise $<0.3 \mathrm{mg} / \mathrm{dl}$ & $\geq 0.5 \mathrm{ml} / \mathrm{kg}$ per $\mathrm{h}$ \\
\hline 1 & $\begin{array}{l}\text { Serum creatinine rise } \geq 0.3 \mathrm{mg} / \mathrm{dl} \text { within } 48 \text { h or } \\
\text { serum creatinine rise } \geq 1.5-1.9 \times \text { reference serum } \\
\text { creatinine }{ }^{\mathrm{a}} \text { within } 7 \text { days }\end{array}$ & $\begin{array}{l}<0.5 \mathrm{ml} / \mathrm{kg} \text { per } \mathrm{h} \text { for } \\
6-12 \mathrm{~h}\end{array}$ \\
\hline 2 & $\begin{array}{l}\text { Serum creatinine rise } \geq 2.0-2.9 \times \text { reference } \\
\text { serum creatinine }^{\mathrm{a}}\end{array}$ & $\begin{array}{l}<0.5 \mathrm{ml} / \mathrm{kg} \text { per } \mathrm{h} \text { for } \\
\geq 12 \mathrm{~h}\end{array}$ \\
\hline 3 & $\begin{array}{l}\text { Serum creatinine rise } \geq 3.0 \times \text { reference serum } \\
\text { creatinine } \text { or serum creatinine } \geq 2.5 \mathrm{mg} / \mathrm{dl} \\
(221 \mu \mathrm{mol} / \mathrm{l})^{\mathrm{b}} \text { or receipt of dialysis }\end{array}$ & $\begin{array}{l}<0.3 \mathrm{ml} / \mathrm{kg} \text { per } \mathrm{h} \text { for } \\
\geq 24 \mathrm{~h} \text { or anuria for } \geq 12 \mathrm{~h}\end{array}$ \\
\hline \multicolumn{3}{|c|}{$\begin{array}{l}\text { Differences between the proposed neonatal modified acute kidney injury (AKI) Kidney } \\
\text { Disease: Improving Global Outcomes (KDIGO) criteria and KDIGO criteria for AKI in children } \\
\text { and adults include the following: areference serum creatinine is defined as the lowest previous } \\
\text { serum creatinine value, and ba serum creatinine value of } 2.5 \mathrm{mg} / \mathrm{dl}(221 \mu \mathrm{mol} / \mathrm{l}) \text { represents } \\
\text { a glomerular filtration rate of }<10 \mathrm{ml} / \mathrm{min} / 1.73 \mathrm{~m}^{2} \text {. Reproduced with permission from REF. }{ }^{31} \text {, } \\
\text { AAP News and Journals Gateway. }\end{array}$} \\
\hline
\end{tabular}

of having a preterm child (adjusted OR 1.33, 95\% CI $1.05-1.67)^{73}$

Body weight. The effect of pre-pregnancy body mass index (BMI) on neonatal outcomes has also been stud$\operatorname{ied}^{74}$. A meta-analysis of $>1$ million pregnancies found that singletons born to underweight women (as defined by the original study) were at higher risk of being preterm (adjusted relative risk (RR) 1.29, 95\% CI 1.15-1.46) and LBW (adjusted RR 1.64, 95\% CI 1.38-1.94) than singletons born to healthy-weight mothers ${ }^{75}$. This relationship between low maternal weight, LBW and prematurity might be explained by the direct effects of nutrient insufficiency on fetal growth and the duration of gestation or by indirect effects of risk factors associated with low maternal weight, such as smoking or the existence of medical conditions ${ }^{75}$. At the other end of the spectrum, an accumulating body of evidence indicates that women who are obese or overweight before pregnancy have an increased risk of adverse neonatal outcomes, including high birthweight and being large for gestational age $\mathrm{e}^{76,77}$. Although the pathophysiological mechanism or mechanisms by which maternal high body weight adversely affects perinatal outcomes are not clear, insulin resistance associated with obesity is likely to have an important role ${ }^{78}$.

Kidney dysfunction and diseases. The prevalence of CKD is around 3\% among women of childbearing age ${ }^{79}$. Data from population-based studies ${ }^{80}$, large prospective cohort studies ${ }^{81}$ and a meta-analysis ${ }^{82}$ indicate that infants born to women with CKD have worse neonatal outcomes than infants of women without CKD, including preterm birth ${ }^{80-82}, \mathrm{LBW}^{80,82}$ and being small for gestational age ${ }^{81,82}$. The rates of these complications increased with severity of $\mathrm{CKD}^{81}$. Adverse neonatal outcomes have also been reported for specific CKD aetiologies. For example, women with diabetic nephropathy and an $\mathrm{SCr}$ level $>1.5 \mathrm{mg} / \mathrm{dl}(132.6 \mu \mathrm{mol} / \mathrm{l})$ in the first trimester of pregnancy have a higher risk of having a VLBW baby (44.4\% versus $5.1 \% ; P=0.004)$ and delivering before 32 weeks gestation $(44.4 \%$ versus $7.7 \% ; P=0.020)$ than women with an SCr level $\leq 1.0 \mathrm{mg} / \mathrm{dl}(88.4 \mu \mathrm{mol} / \mathrm{l})^{83}$. A retrospective analysis of 43 women with diabetic nephropathy and median SCr levels of $0.77 \mathrm{mg} / \mathrm{dl}$ (68 $\mu \mathrm{mol} / \mathrm{l})$ before pregnancy reported much higher rates of poor pregnancy outcomes than anticipated on the basis of the degree of renal dysfunction, including pre-eclampsia in $42 \%$ of patients and preterm birth in $77 \%$ of infants, suggesting that aetiology-specific factors, such as hyperglycaemia, also drive adverse neonatal outcomes $^{84}$.

Two studies published in 2018 reported higher rates of preterm birth (RR 3.2, 95\% CI 2.5-4.1) and LBW (RR 4.2, 95\% CI 3.4-5.3) among offspring of patients with systemic lupus erythematosus than among offspring of population controls ${ }^{85,86}$, although available evidence suggests that the risk of pregnancy complications for women with inflammatory connective tissue diseases has decreased over the past few decades ${ }^{87}$. Notably, the effect of lupus nephritis on neonatal outcomes depends on the activity of renal disease. Active lupus nephritis during pregnancy is associated with a higher incidence of maternal ${ }^{88}$ and neonatal complications ${ }^{86,88,89}$ than is seen in those with inactive disease. Hypocomplementaemia or positivity for antibodies to double-stranded DNA consistently correlate with increased rates of miscarriage and preterm birth ${ }^{90}$. Women with a combination of high clinical disease activity and serological markers of systemic lupus erythematosus face the highest risk of adverse pregnancy outcomes ${ }^{90}$.

Chronic hypertension complicates about $1-4 \%$ of pregnancies $^{91}$. A meta-analysis involving $>750,000$ women from studies in the USA found that the incidence of superimposed pre-eclampsia (RR 7.7, 95\% CI 5.7-10.1), preterm delivery (RR 2.7, 95\% CI 1.9-3.6), LBW (RR 2.7, 95\% 1.9-3.8), NICU admission (RR 3.2, 95\% CI 2.2-4.4) and perinatal death (RR 4.2,95\% CI 2.7-6.5) was higher in pregnant women with chronic hypertension than in those from the US national population data set ${ }^{92}$.

Interval between pregnancies. In addition to the aforementioned pre-gestational conditions, both short and long intervals between pregnancies are associated with unfavourable neonatal outcomes, including preterm birth, LBW and neonates small for gestational age ${ }^{93,94}$. By analysing two interpregnancy intervals per mother in a sample of 40,441 mothers, Ball et al. showed that an interpregnancy interval $<6$ months was associated with a very small increase in the risk of having a preterm (adjusted OR 1.07, 95\% CI 0.86-1.34), LBW (adjusted OR 1.03, 95\% CI 0.79-1.34) or small for gestational age (adjusted OR 1.08, 95\% CI 0.87-1.34) child compared with the reference interpregnancy interval of 18-23 months. This study enabled each mother to act as her own control for risk factors that vary greatly among women but tend to persist between pregnancies, such as genetic predisposition, lifestyle or social conditions $s^{95}$.

\section{Gestational risk factors}

Assisted reproductive technologies. Worldwide, $>5$ million babies have been born as a result of assisted reproductive technologies (ART), including in vitro fertilization $^{96,97}$. Pregnancies conceived using ART are at increased risk of adverse perinatal outcomes, with 
Spontaneously conceived Conception without the use of any medical interventions; also referred to as natural conception. much of this risk being ascribed to multiple-gestation pregnancies. Indeed, twins resulting from ART pregnancies have a greater than tenfold increase in the odds of being premature (OR 11.84, 95\% CI 10.56-13.27) or LBW (OR 10.68, 95\% CI 9.45-12.08) than singletons from ART pregnancies ${ }^{98}$. Of note, however, even singleton ART pregnancies are subject to higher rates of preterm birth than spontaneously conceived singletons (RR 2.13, 95\% CI 1.26-3.61) ${ }^{99}$. Subfertility and/or its causes, the controlled ovarian hyperstimulation before ART or the ART procedure itself have been suggested to influence the neonatal outcomes of singleton pregnancies resulting from in vitro fertilization ${ }^{100,101}$.

Genetic susceptibility. A substantial body of evidence supports a role for genetic factors - mainly from the maternal genome - in the regulation of fetal development ${ }^{63,102-106}$. A large genome-wide association study (GWAS) of samples from $>43,000$ women of European ancestry, replicated in samples from an additional 8,643 women from three Nordic Birth studies ${ }^{107,108}$, identified six loci - EBF1, EEFSEC, AGTR2, WNT4, ADCY5 and $R A P 2 C$, which encode proteins with functions consistent with the timing of birth, such as maintaining redox status and antioxidant defences, and in modulating uteroplacental circulation - as being significantly associated with gestational duration ${ }^{107}$. Notably, three of these loci (EBF1, EEFSEC and AGTR2) were associated with spontaneous preterm birth. The mechanisms by which these loci affect spontaneous birth remain speculative; it is unclear whether EBF1 modulates pregnancy-specific pathways or general cardiovascular or metabolic signals that influence gestation. Variants at the EEFSEC locus might affect incorporation of the cysteine analogue, selenocysteine, into selenoproteins, which in turn might affect cellular homeostasis functions favouring spontaneous preterm birth ${ }^{107}$. Variants within the AGTR2 locus contribute to the risk of preeclampsia ${ }^{109}$, which is a possible cause of premature delivery. However, these Nordic Birth studies excluded preterm births associated with pre-eclampsia, indicating a direct association between AGTR2 variants and prematurity. IUGR is also in part genetically regulated, with various polymorphisms thought to have a role in different ethnic groups ${ }^{110}$. For example, polymorphisms in maternal and fetal genes that encode proteins involved in extracellular matrix metabolism affect the risk of being born small for gestational age ${ }^{111}$, whereas in the placenta, polymorphism in the promoter of SERPINA3 - a gene that encodes a protein involved in a wide range of biological processes, including coagulation, inflammation and wound healing - is associated with IUGR ${ }^{112}$.

Epigenetic regulation of pregnancy outcomes. Gene expression can be modulated through epigenetic processes in response to environmental, nutritional and lifestyle factors ${ }^{113}$; available evidence suggests that epigenetic modifications at around the time of conception and during gestation contribute to IUGR by modulating gene expression through effects on histone modifications ${ }^{114,115}$, DNA methylation ${ }^{116-119}$ and microRNA expression $^{120,121}$.
Maternal caloric restriction can affect the health not only of the direct offspring but also of future generations $^{122,123}$, although the role of epigenetic inheritance in this context remains unclear. In a mouse model of gestational undernutrition characterized by LBW, glucose intolerance and reduced pancreatic function for two subsequent generations, maternal caloric restriction resulted in hypomethylation of discrete loci in sperm and somatic tissues of first-generation male offspring. However, this differential methylation pattern did not persist in somatic tissues of the second-generation progeny, indicating that the LBW and metabolic phenotype observed in this generation did not result from longterm heritable memory of compromised male germ line development and DNA methylation reprogramming ${ }^{124}$. These data suggest that epigenetic mechanisms other than DNA methylation, such as histone modifications or small non-coding RNAs, are responsible for the persistence of the altered metabolic phenotype in subsequent generations ${ }^{125}$.

Nutrition. As mentioned in the previous section, neonatal outcomes also depend on maternal nutritional status. Adequate gestational weight gain is crucial for meeting maternal and fetal nutritional needs during pregnancy, and both insufficient and excessive gestational maternal weight gain adversely affect neonatal outcomes. A 2017 meta-analysis of $>1,300,000$ pregnancies reported that gestational weight gain below that recommended by the 2009 Institute of Medicine (IOM) guidelines ${ }^{126}$ was associated with a higher risk of preterm birth infants (OR 1.70, 95\% CI 1.32-2.20) and of the neonate being small for gestational age (OR 1.53, 95\% CI 1.44-1.64) ${ }^{127}$. Conversely, women who gained more weight than recommended by the IOM had an increased risk of Caesarean delivery (OR 1.30, 95\% CI 1.25-1.35) and of the neonate being large for gestational age (OR 1.85, 95\% CI 1.76-1.95 $)^{127}$. The composition of maternal diet during gestation can also influence fetal growth and birth size. Similar to experimental studies, which have mostly shown that maternal protein restriction leads to reduced birthweight of offspring ${ }^{128}$, some, but not all, human studies have shown an association between low protein intake during pregnancy and lower birthweight ${ }^{129-133}$. Differences in baseline nutritional status between study populations, the gestational time at which diet was evaluated and methods for dietary ascertainment might account for inconsistent findings between studies.

Smoking and alcohol consumption. Maternal lifestyle, such as alcohol and tobacco consumption habits, also affects birth outcomes. It is now well established that heavy alcohol consumption during pregnancy increases the risk of giving birth to preterm, LBW and small for gestational age infants ${ }^{134}$. However, lack of consensus exists regarding the effect of low to moderate maternal alcohol consumption, with studies and evidence reviews reporting a broad spectrum of effects associated with light alcohol consumption ${ }^{135-138}$. Similar to heavy alcohol consumption, tobacco smoking during pregnancy is associated with an increased risk of having 


\section{Peripartum period \\ The peripartum period spans from the last month of gestation to 5 months after delivery. \\ Perinatal asphyxia Also known as birth asphyxia, it is the failure to initiate and sustain respiration at birth. \\ Diaphragmatic hernia \\ The presence of a defect in the diaphragm that allows \\ herniation of some abdominal viscera into the thoracic cavity, causing respiratory distress at birth with or without pulmonary hypoplasia and/or hypertension.}

preterm, LBW and small for gestational age infants ${ }^{139-141}$. Nicotine, the major tobacco alkaloid, has been posited to adversely affect gestational parameters, mainly by inducing vasoconstriction of uteroplacental blood vessels, which eventually reduces placental blood flow and the delivery of nutrients and oxygen to the fetus ${ }^{142}$. Intriguingly, mounting evidence suggests that derangements in epigenetic placental and fetal (re)programming are one mechanism involved in the association between prenatal tobacco exposure and fetal growth impairment ${ }^{143-145}$.

Exposure to nephrotoxic medications. Maternal exposure to angiotensin-converting enzyme (ACE) inhibitors and angiotensin type 1 receptor antagonists can impair the development and function of the perinatal kidney ${ }^{146}$, leading to varying degrees of renal papillary atrophy, impaired urinary concentrating ability ${ }^{147}$ and renal failure ${ }^{148}$ depending on the timing and duration of exposure. Similarly, nonsteroidal anti-inflammatory drugs, such as indomethacin, can cause renal vasoconstriction by inhibiting cyclooxygenases and prostaglandin synthase ${ }^{149}$ and might adversely affect renal function in the developing fetus. Fetal urine output declines markedly within $5 \mathrm{~h}$ of indomethacin administration to pregnant women - an effect that has also been documented following antenatal exposure to ibuprofen and ketoprofen ${ }^{150}$. Notably, women who are at risk of preterm delivery are sometimes administered indomethacin in the peripartum period, which can predispose neonates to transient or persistent oliguria and AKI ${ }^{150-152}$.

Pregnancy-related complications. Pregnancy-related complications can also affect neonatal outcomes. In particular, pre-eclampsia affects about $3-5 \%$ of pregnancies $^{153}$ and is associated with an increased risk of premature birth (adjusted OR 2.86, 95\% CI 2.68-3.06) and LBW in infants (adjusted OR 2.32, 95\% CI 2.16-2.50) ${ }^{154}$. Notably, both pre-eclampsia and LBW are independent risk factors for recurrence of pre-eclampsia and LBW in subsequent generations, providing evidence for the intergenerational impact of developmental programming $^{155}$.

\section{Postnatal risk factors for AKI}

As mentioned earlier, premature and LBW neonates are at increased risk of AKI at least in part owing to impaired nephrogenesis and low nephron endowment ${ }^{156}$. Premature and LBW infants are also often affected by comorbidities such as sepsis, necrotizing enterocolitis, use of nephrotoxic medications and dehydration due to excessive urine output ${ }^{157}$ such that the comorbidities themselves are risk factors for AKI. Moreover, despite being born with a full complement of nephrons, critically ill near-term and term neonates are at increased risk of developing AKI and its sequelae. Most cases of AKI in neonates are multifactorial, resulting from a combination of sepsis and reduced renal blood flow secondary to a decrease in intravascular volume (for example, from blood loss, excessive gastrointestinal losses and increased insensible fluid loss in premature neonates with immature skin $)^{60}$.
Cardiac and respiratory risk factors. Perinatal asphyxia resulting from deprivation of oxygen is one reason for ICU admission that is associated with an increased risk of neonatal AKI. In one single-centre study, AKI occurred in $38 \%$ of 96 asphyxiated neonates undergoing therapeutic hypothermia ${ }^{39}$. The incidence of AKI was related to the extent of perinatal asphyxia, ranging from $9.1 \%$ to $56 \%$ among infants with moderate or severe asphyxia, respectively ${ }^{158}$.

Cardiac and respiratory involvement in neonates, including complex congenital heart diseases that affect the systemic circulation, and the need for interventions, such as cardiopulmonary bypass surgery, medications to maintain blood pressure, high-frequency ventilation and ECMO, are also associated with neonatal AKI ${ }^{159-161}$. A multicentre study reported that AKI occurred in $26 \%$ of neonates requiring ECMO for non-cardiac reasons. After adjustment, AKI in this population was associated with a 3.2-fold increase in mortality compared with neonates who did not develop AKI ${ }^{41}$. Similar findings were reported for neonates with congenital diaphragmatic hernia on ECMO, in whom AKI occurred in $71 \%$, with $73 \%$ mortality in those with the highest stage of AKI, defined as a doubling of SCr (stage 2 or higher AKI by Acute Kidney Injury Network (AKIN)

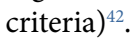

Sepsis. Neonatal sepsis is a cause of substantial morbidity and mortality. A study from the Eunice Kennedy Shriver National Institute of Child Health and Human Development (NICHD) National Research Network estimated the overall rate of early-onset sepsis, defined as a positive blood or cerebrospinal culture $<72 \mathrm{~h}$ following birth, to be 0.98 cases per 1,000 live births. Infection rates were inversely associated with gestational age and birthweight (affecting 10.96 per 1,000 live births for infants with birthweights of 401-1,500 g, 1.38 per 1,000 live births for infants with birthweights of $1,501-2,500 \mathrm{~g}$ and 0.57 per 1,000 live births for infants with birthweights $>2,500 \mathrm{~g})^{162}$. An immature immune system and need for invasive medical procedures (for example, prolonged intravenous access and endotracheal intubation) that impair barrier and clearance functions place preterm infants at increased risk of hospital-acquired infections ${ }^{163}$. In addition, the humoral immune response is considerably reduced in preterm infants because transplacental passage of maternal IgG antibodies begins at about 13 weeks of gestation, with the largest amount being transferred during the third trimester ${ }^{164}$.

Sepsis is a major cause of AKI in neonates, with some studies estimating that sepsis contributes to $78 \%$ of AKI cases $^{28,165-167}$. In a cohort of 200 full-term neonates with sepsis, 26\% developed AKI. Infants that developed AKI had the lowest birthweights of the cohort and were more likely than infants who did not develop AKI to also develop septic shock in addition to other comorbidities such as meningitis and disseminated intravascular coagulation ${ }^{36}$. The predisposition of septic neonates to AKI has been attributed to hypotension associated with systemic inflammation ${ }^{168}$; however, the occurrence of AKI in septic neonates with normal systemic blood 


\section{Box 1 |Commonly used nephrotoxins}

Various nephrotoxic agents are commonly adminstered to critically ill neonates. These agents and their renal effects are detailed below.

Antimicrobial and antimycotic medications
Aminoglycosides
- Inhibition of lysosomal phospholipase and increased
oxidative stress in the proximal tubule
- Intrarenal vasoconstriction
- Mesangial cell contraction in glomeruli
Amphotericin B
- Increased epithelial membrane permeability in the
distal tubule
- Intrarenal vasoconstriction
- Inappropriate activation of tubuloglomerular feedback
Antiviral medications
Acyclovir
- Intratubular crystal deposition
- Tubular obstruction
Nonsteroidal anti-inflammatory drugs
Indomethacin, ibuprofen and ketoprofen
- Acute interstitial nephritis
- Inhibition of vasodilator prostaglandin production
- Glomerular filtration rate decline
Intravenous immunoglobulins
- Osmotic injury caused by the sucrose contents of the
intravenous immunoglobulin formulations
Radiocontrast agents
- Increased oxidative stress in the tubules
- Intrarenal vasoconstriction

pressure and renal blood flow suggests a direct effect of sepsis on the kidney, possibly through dysregulation of the microcirculation ${ }^{168-171}$.

Nephrotoxic agents. Nephrotoxic agents deserve particular consideration in terms of their role in increasing AKI risk. Critically ill neonates, who are already at increased risk of developing AKI, often receive medications that further increase susceptibility to $\mathrm{AKI}^{46,62,152}$. Many of these medications (for example, ibuprofen and gentamicin) are predominantly cleared through renal filtration and secretory pathways. Impairments in these clearance pathways lead to progressive increases in drug concentrations in the tubular lumen and might promote nephrotoxicity ${ }^{46,152}$. Interestingly, term neonates might be more susceptible than premature neonates to druginduced nephrotoxicity because the unique mechanisms of the immature tubular transport system - which is unable to resorb the nephrotoxic medication into the cell - are thought to provide some protection against the nephrotoxic effects of agents that are cleared via renal tubular transport pathways ${ }^{172}$. However, studies in rats suggest that the administration of nephrotoxic medications to preterm progeny impairs any ongoing postnatal nephrogenesis ${ }^{173}$. This observation is relevant given that most therapeutic agents used in the NICU have not been tested for safety, dosing and efficacy in infants and are not specifically labelled for use in neonates. Of interest, a study of paediatric labelling changes to the US Food and Drug Administration (FDA) registry as a result of changes to federal legislation found that only 24 of $>400$ (6\%) such changes made between 1997 and 2010 provided new information relating to the use of these drugs in neonates ${ }^{174}$. The need for further information about the nephrotoxicity of medications given to neonates is highlighted by a 2014 epidemiologic study of 107 VLBW infants, which found that these neonates were frequently exposed to potentially nephrotoxic medications during their stay in the ICU, with $87 \%$ of neonates receiving at least one potentially nephrotoxic compound for an average treatment duration of 2 weeks ${ }^{46}$. The greatest exposure occurred among the smallest and most immature neonates and in those who experienced AKI.

Available evidence suggests that a number of nephrotoxic agents are commonly used in the NICU (BOX 1). Aminoglycosides, which are the mainstay treatment for neonates with suspected sepsis or documented severe Gram-negative infections, accumulate in the proximal tubules, where they inhibit lysosomal phospholipase, disrupt mitochondrial ATP production and promote oxidative stress, leading to cell death ${ }^{175-177}$. In addition to their toxic effects on the tubular epithelium, evidence also indicates that aminoglycosides cause intrarenal vasoconstriction and glomerular mesangial cell contraction, which eventually impairs glomerular haemodynamics ${ }^{178}$. As a result, aminoglycoside nephrotoxicity leads to a number of electrolyte abnormalities and, in the most severe cases, acute tubular necrosis, oliguria and renal failure in LBW neonates or in those exposed concomitantly to other nephrotoxic drugs $\mathrm{s}^{175,179}$.

Amphotericin B is commonly used in critically ill neonates to prevent mycotic infections ${ }^{180}$; antimycotic drugs exert nephrotoxic effects in the distal tubule and cause renal vasoconstriction ${ }^{181,182}$. By inserting into cell membranes ${ }^{182}$, amphotericin B also increases the membrane permeability of macula densa cells to sodium chloride, leading to inappropriate tubuloglomerular feedback, afferent arteriolar vasoconstriction and GFR decline ${ }^{183}$. Although incompletely understood, these mechanisms account for the electrolyte abnormalities and renal function impairment seen with administration of amphotericin $B$, which in neonates are usually transient but can be associated with considerable morbidity ${ }^{184}$. Liposomal formulations of amphotericin B, developed to reduce toxicity, have been reported by some studies to be less nephrotoxic in premature neonates, with the incidence of nephrotoxicity ranging from $0 \%$ to $20 \%^{185-187}$; however, the lower nephrotoxicity of the liposomal formulations than of conventional formulations is not widely accepted $^{186}$.

In addition to other antimicrobial and antiviral medications, as well as intravenous immunoglobulins, which can all cause nephrotoxicity ( $\mathrm{BOX} 1$ ), neonatologists and intensivists should consider the risk of AKI associated with the use of radiocontrast agents. Although the mechanisms of contrast-induced nephrotoxicity are incompletely understood, animal studies suggest that hypoxic medullary injury has a critical role ${ }^{188}$. 


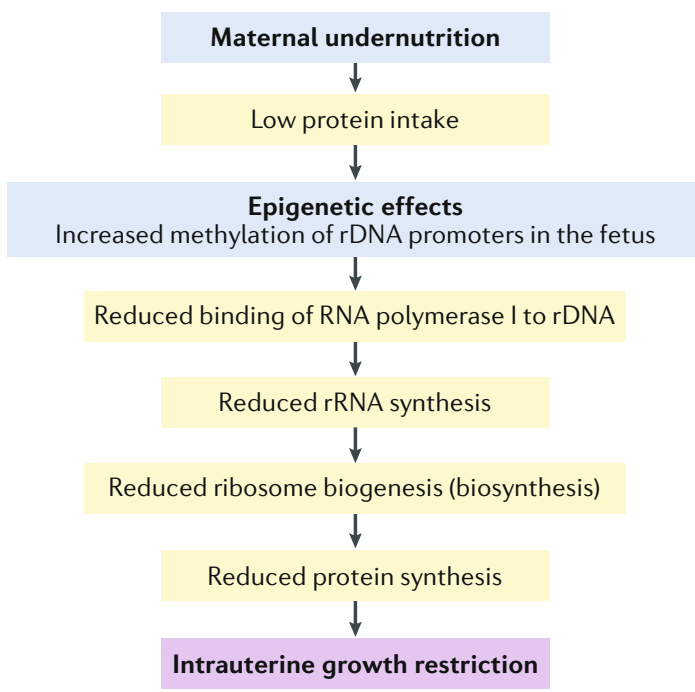

Fig. 2 | Maternal diet regulates epigenetic processes that influence fetal growth as demonstrated by studies in mice fed a low-protein diet during early gestation. Low protein intake in early pregnancy might increase the extent of methylation on the promoter of ribosomal DNA $(\mathrm{rDNA})$ in the fetus. This increased methylation reduces the binding of the enzyme RNA polymerase I to rDNA, thereby reducing ribosomal synthesis and eventually ribosomal biogenesis. As a result, fetal protein synthesis is downregulated and intrauterine growth is impaired. rRNA, ribosomal RNA.

\section{Management of maternal risk factors}

The early identification of risk factors that increase the risk of preterm birth and LBW - including genetic pregestational and gestational risk factors - is essential to identify approaches to reduce the risk of these adverse pregnancy outcomes ${ }^{189-191}$.

Macronutrients and micronutrients, including vitamins, calcium and zinc, influence fetal phenotypic adaptation by influencing the availability of methyl donors and mechanisms promoting DNA stability ${ }^{192-195}$ and could therefore be considered a nutritional intervention to promote intrauterine growth. This possibility is supported by findings from experimental animal studies that have highlighted the importance of maternal diet in regulating epigenetic processes that influence fetal growth ${ }^{196-198}$. These processes are particularly relevant in the periconceptional period, as exemplified by the finding that a low-protein diet fed to mice specifically during the last few days of oocyte maturation ${ }^{199}$ or during the short time of preimplantation embryo development ${ }^{200,201}$ induced responses in the placenta through epigenetic mechanisms that affected the rate of ribosome biogenesis, eventually affecting protein synthesis and intrauterine fetal growth ${ }^{202,203}$. Indeed, administration of a low-protein diet downregulates expression of ribosomal RNA in mice - an effect that was reversed upon restoration of a normal diet ${ }^{204}$. Although the exact mechanisms by which protein insufficiency affects ribosome biogenesis are unclear, it has been suggested that the concentration of nutrients within the uterus regulates the extent of methylation on the promoter of ribosomal DNA, which thereby affects its ability to interact with RNA polymerase I and modulates ribosome biogenesis ${ }^{204}$. Evidence also suggests that administration of a low-protein diet to pregnant mice modifies the trophoblast phenotype to regulate fetal growth by enhancing the transfer of nutrients to the fetus, although whether epigenetic processes are involved in this effect has not been investigated ${ }^{205}$ (FIG. 2). Notably, the presence of these epigenetic alterations has been documented in rural Gambians, who experience dramatic nutritional challenges during the rainy season. These seasonal variations affect the methyl-donor nutrient intake of mothers and can alter tissue DNA methylation at conception $^{206,207}$, but the effects of these epigenetic alterations on pregnancy outcomes have not been studied.

Evidence also suggests that administration of a protein-restricted diet to pregnant rats induces transcription of the genes encoding nuclear receptors glucocorticoid receptor and peroxisome proliferator-activated receptor- $\alpha$ (PPAR $\alpha$ ) in the liver of the offspring by inducing hypomethylation of their respective promot$\mathrm{ers}^{208}$, possibly by reducing DNA methyltransferase 1 expression ${ }^{209}$. Supplementation of the protein-restricted diet with folic acid prevented promoter hypomethylation and attenuated the increase in glucocorticoid receptor and PPARa expression ${ }^{208}$. In addition, the impairment of placental growth in malnourished pregnant rats has been attributed to cell apoptosis secondary to reduced energy substrates for mitochondrial function $^{192}$, but its relationship with epigenetic alterations remains unclear. Together, these observations suggest that nutritional changes affect epigenetic processes such as DNA methylation and histone deacetylation to regulate the expression of factors involved in stress and metabolic responses, such as the glucocorticoid receptor and PPARa, and might be a target for therapeutic intervention ${ }^{192}$.

Indeed, improving nutritional status during pregnancy can positively affect birth outcomes. A 2015 analysis of 23 systematic reviews of randomized controlled trials of nutritional interventions given before and during pregnancy showed that oral supplementation with vitamin A, low-dose calcium, zinc and multiple micronutrients (defined as supplements that contain more than three micronutrients ${ }^{210}$ ) was associated with a reduction in the risk of $\mathrm{LBW}^{211}$. Nutritional interventions containing multiple micronutrients and supplements with balanced protein-energy content also reduced the risk of neonates being born small for gestational age, whereas zinc or long-chain $n-3$ fatty acid supplementation significantly decreased the risk of preterm birth. Most evidence in support of these interventions, however, comes from a small number of trials, often with a limited number of participants, indicating the need for larger trials to reach more robust conclusions about the impact of nutritional interventions on pregnancy outcomes $^{211}$. Of note, only few human studies to date have examined the contribution of epigenetic modifications to the relationship between maternal diet supplementation and birth outcomes. One study analysed the methylome of cord blood samples from 12 women, of whom 8 were given folic acid supplementation during pregnancy, and found a significant correlation between 
the methylation status of $16 \mathrm{CpG}$ loci with birthweight percentile, cord plasma homocysteine concentrations (an inverse measure of folate status) and global DNA methylation ${ }^{212}$. Although this study did not investigate the mechanism or mechanisms that link variations in DNA methylation to birthweight, the findings support an association between folic acid supply, changes in the epigenome and offspring phenotype.

\section{Management of neonatal AKI}

Despite the burden of AKI, no approved pharmacologic agents exist to treat neonates who develop AKI. Interventions are therefore confined to the management of sequelae associated with the acute renal insult, including the use of renal replacement therapy (RRT) in the form of dialysis to support the neonate while the kidney is unable to maintain proper fluid and electrolyte homeostasis.

Particular care should be taken to monitor fluid balance and the quantity of both fluid input and output documented. Neonates with AKI are usually nonoliguric, but in some cases infants develop oliguric or anuric renal failure that leads to fluid overload ${ }^{213}$, which is an independent risk factor for morbidity and mortality independent of the severity of neonatal illness ${ }^{214,215}$. In the setting of oliguric or anuric renal failure, diuretics are frequently used in an attempt to maintain urine output, despite the absence of specific guidelines for this treatment in infants with AKI. Patients who are not responsive to initial treatment with $1-1.5 \mathrm{mg} / \mathrm{kg}$ furosemide do not benefit from further diuretics and should be considered for early RRT ${ }^{216,217}$. Limited evidence also suggests that in $\mathrm{VLBW}^{218}$ and preterm infants with $\mathrm{AKI}^{219}$, the beneficial effect of the loop diuretic bumetanide on urine output occurs at the expense of worsening renal failure, indicated by an increase in $\mathrm{SCr}$ level, suggesting that diuretics should be used with caution in these patients. Serum electrolyte disturbances should also be adequately monitored and properly managed, in particular hyperkalaemia, a life-threatening complication of AKI.

The lack of any specific treatment for AKI has led to renewed interest in identifying interventions to prevent AKI in at-risk patients. The adenosine receptor antagonist theophylline has demonstrated renal benefits in randomized studies of neonates with perinatal asphyxia, possibly by inhibiting adenosine-induced vasoconstriction and improving renal blood flow ${ }^{220-223}$. On the basis of available evidence, this methylxanthine is recommended by KDIGO for routine use in neonates with perinatal asphyxia who are at high risk of $\mathrm{AKI}^{52}$, but the potential neurologic adverse effects of the drug should be considered carefully ${ }^{224}$. Further studies on theophylline should be performed in the context of new clinical guidelines for systemic hypothermia in asphyxiated infants to determine whether the addition of this or other agents can reduce short-term or long-term morbidity and mortality.

Another methylxanthine, caffeine, a medication commonly used to assist in the extubation of premature infants ${ }^{225}$, might also protect against AKI. In the AWAKEN cohort, premature infants who received caffeine had much lower rates of AKI than those who did not receive caffeine $(11.2 \%$ versus $31.6 \% ; P<0.01)$. Caffeine remained associated with reduced odds of developing AKI even after multivariable adjustment (adjusted OR 0.2, 95\% CI 0.11-0.34), indicating that

Table 3 | Findings from long-term studies of CKD sequelae in term and preterm NICU graduates

\begin{tabular}{|c|c|c|c|c|c|}
\hline Study & Aetiology (n) & $\begin{array}{l}\text { Mean years } \\
\text { at follow-up } \\
\text { (range) }\end{array}$ & $\begin{array}{l}\text { CKD } \\
\text { rate }\end{array}$ & $\begin{array}{l}\text { Method to assess } \\
\text { CKD }\end{array}$ & $\begin{array}{l}\text { Comparison of outcomes for } \\
\text { survivors of AKI compared } \\
\text { with those without AKI }\end{array}$ \\
\hline \multicolumn{6}{|c|}{ Full-term infants } \\
\hline $\begin{array}{l}\text { Polito et al. } \\
(1998)^{257}\end{array}$ & Asphyxia (6) & $8.0(6.5-19)$ & $83 \%$ & $\begin{array}{l}\text { eGFR }<90 \mathrm{ml} / \\
\mathrm{min} / 1.73 \mathrm{~m}^{2} \text { and } \mathrm{BP} \\
>95 \text { th percentile }\end{array}$ & NA \\
\hline $\begin{array}{l}\text { Zwiers et al. } \\
(2014)^{258}\end{array}$ & ECMO (169) & $8.2(5.2-12.1)$ & $32 \%$ & $\begin{array}{l}\text { eGFR }<90 \mathrm{ml} / \\
\mathrm{min} / 1.73 \mathrm{~m}^{2}, \mathrm{BP} \\
>95 \text { th percentile and } \\
\text { proteinuria }\end{array}$ & More CKD \\
\hline $\begin{array}{l}\text { Cooper et al. } \\
(2016)^{259}\end{array}$ & $\mathrm{CHD}(51)$ & $8.0(6.9-9.6)$ & $9 \%$ & $\begin{array}{l}\mathrm{eGFR}<90 \mathrm{ml} / \\
\mathrm{min} / 1.73 \mathrm{~m}^{2}\end{array}$ & $\begin{array}{l}\text { Higher urinary IL-18 and liver- } \\
\text { type fatty acid binding protein }\end{array}$ \\
\hline \multicolumn{6}{|c|}{ Premature infants } \\
\hline $\begin{array}{l}\text { Abitbol et al. } \\
(2003)^{242}\end{array}$ & ELBW (20) & $7.5(3.2-18.5)$ & $45 \%$ & $\begin{array}{l}\mathrm{eGFR}<75 \mathrm{ml} / \\
\mathrm{min} / 1.73 \mathrm{~m}^{2}\end{array}$ & NA \\
\hline $\begin{array}{l}\text { Bruel et al. } \\
(2016)^{260}\end{array}$ & $\begin{array}{l}<33 \text { week GA } \\
\text { (74) }\end{array}$ & $6.6(3.0-10.0)$ & $30 \%$ & $\begin{array}{l}\text { eGFR }<90 \mathrm{ml} / \\
\mathrm{min} / 1.73 \mathrm{~m}^{2}, \mathrm{BP} \\
>95 \text { th percentile and } \\
\text { albuminuria }\end{array}$ & Lower total kidney volume \\
\hline $\begin{array}{l}\text { Harer et al. } \\
(2017)^{251}\end{array}$ & VLBW (34) & $5.0(4.0-6.0)$ & $44 \%$ & $\begin{array}{l}\text { eGFR }<90 \mathrm{ml} / \\
\mathrm{min} / 1.73 \mathrm{~m}^{2}, \mathrm{BP} \\
>95 \text { th percentile and } \\
\text { albuminuria }\end{array}$ & More CKD \\
\hline
\end{tabular}


Pre-gestational maternal risk factors

- Socio-economic determinants

- Poverty

- Low education

- No occupation

- Environmental stress

- Underweight

- CKD

- Hypertension

IUGR, LBW and preterm birth

Associated impaired renal development and/or low nephron number

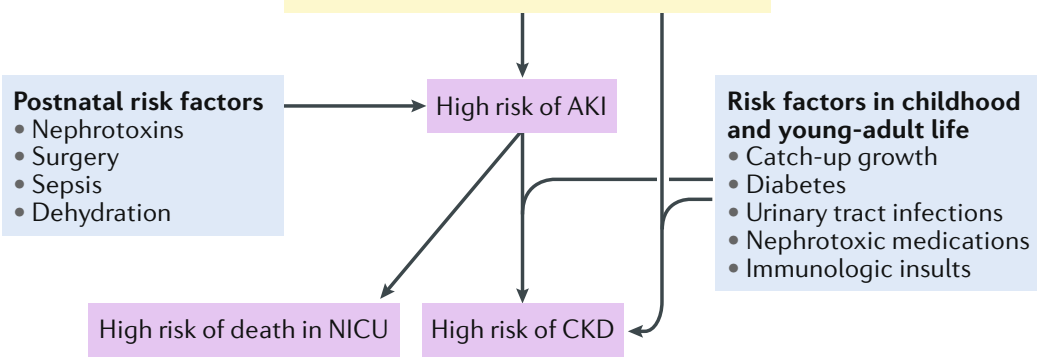

Fig. 3 | Pre-gestational and gestational risk factors for intrauterine growth restriction, low birthweight and preterm birth, which are associated with impaired renal development and low nephron number. In this framework, comorbidities and/or nephrotoxic medications in critically ill neonates might precipitate the already increased risk of acute kidney injury (AKI) associated with prematurity or low birthweight (LBW). Among AKI survivors, superimposed events in childhood and young-adult life might further increase the risk of developing chronic kidney disease (CKD). Infants born prematurely or with LBW might also be at risk of CKD independently of AKI development owing to their impaired renal development and low nephron endowment. IUGR, intrauterine growth restriction; $\mathrm{NICU}$, neonatal intensive care unit.

1 case of AKI was prevented for every 4.3 neonates exposed to caffeine ${ }^{226}$.

Mixed results have been reported with other vasodilators, such as the dopaminergic agonist fenoldopam. In small trials, even high-dose fenoldopam given to neonates failed to reduce the overall incidence of AKI following surgery for congenital heart disease, although one minor benefit was a reduced need for postoperative diuretics and vasodilators ${ }^{227,228}$. At this time, firm recommendations cannot be made regarding the use of fenoldopam to prevent AKI in critically ill neonates ${ }^{52}$.

One key area for intervention in critically ill neonates that is often underappreciated is the careful evaluation of exposure to potentially nephrotoxic medications. Neonates should only receive nephrotoxic medications that they need and for only the duration required. Infants exposed to these medications should be closely screened for nephrotoxin-associated AKI, and evaluation of drugs required should be performed daily to limit the harm induced by the medications. As in children and adults, drugs given to infants with AKI can change their pharmacokinetics and pharmacodynamics owing to changes in the absorption, distribution, metabolism and excretion of medicines ${ }^{22}$. When alternative effective medications are available, clinicians should avoid nephrotoxic medicines. In the absence of alternative non-nephrotoxic medications, the minimal effective drug dose should be given to reduce the nephrotoxic burden; avoidance of harmful drug-drug interactions should be attempted. Although no clear guidelines are available with regard to dosing or using concomitant medications in neonates with AKI, the stepwise clinical recommendations proposed by KDIGO in adults with AKI could be helpful in facilitating drug dosing in critically ill neonates and thereby limiting the risk of $\mathrm{AKI}^{229}$.

In order to mitigate nephrotoxin-associated AKI in children, researchers at Cincinnati Children's Hospital have developed an automated screening system called Nephrotoxic Injury Negated by Just-in-time Action (NINJA), which extracts data from electronic medical records to identify children who are receiving at least three nephrotoxic medications or aminoglycosides for a duration of $>3$ days. Patients identified using this system received systematic surveillance with daily assessment of SCr levels. Over 3 years, use of this screening system resulted in a $38 \%$ decrease in the use of nephrotoxic medications in non-critically ill hospitalized children and a $64 \%$ decline in the rate of $\mathrm{AKI}^{230}$. Similar programmes have shown comparable reductions in AKI in critically ill newborn babies in the NICU (D.A., unpublished observations) and highlight the potential to reduce the burden of nephrotoxin exposure in neonates to limit the risk of AKI in vulnerable infants.

RRT is indicated when a risk of impending harm exists owing to an inability of the kidney to function properly. RRT should be considered for a number of complications, including refractory acidosis, electrolyte abnormalities, fluid overload and the inadequate nutrition despite conservative management. For example, and as described above, fluid overload, a potentially modifiable risk factor for mortality in critically ill children ${ }^{231}$ and in sick late preterm neonates with $\mathrm{AKI}^{38}$, can be prevented with careful fluid provision and early RRT initiation. Unfortunately, however, RRT is infrequently used in neonates owing to the challenges associated with its use in this population, including haemodynamic instability during initiation, coagulopathy, acidosis, hypocalcaemia, thrombocytopenia and decreased circuit survival.

Use of adult RRT machines in neonates increases the risk of complications owing in part to the size of the extracorporeal circuit compared with the blood volume of the neonate. Newer RRT machines designed for newborn babies (for example, continuous RRT machines with small extracorporeal volumes) should minimize these risks ${ }^{232-234}$; however, further evaluation of these technologies in large multicentre studies is needed to determine their optimal timing and dose in order to minimize risk and optimize outcomes for neonates. Peritoneal dialysis is still the RRT modality of choice for critically ill neonates with AKI in most centres ${ }^{235-239}$, provided the infant's abdominal wall or cavity is preserved, there are no skin infections and there is no need for high ultrafiltration to manage fluid overload.

\section{Long-term renal sequelae of neonatal AKI}

Depending on the aetiology of $\mathrm{AKI}^{240}$, the degree of prematurity ${ }^{24}$ and the severity of AKI, most critically ill neonates survive after $\mathrm{AKI}^{241}$, as demonstrated in the AWAKEN study, in which approximately $90 \%$ of infants with AKI survived to NICU discharge ${ }^{47}$. However, survivors of AKI are not without long-term renal problems ${ }^{242}$, with studies in animal model ${ }^{243}$, 
critically ill children ${ }^{244,245}$ and adults with $\mathrm{AKI}^{246}$ consistently documenting that an acute kidney insult can result in permanent kidney damage $e^{247,248}$ and promote the development of CKD. In a prospective cohort of 126 children who developed AKI in the paediatric ICU, $10 \%$ of patients had reduced GFR $\left(<60 \mathrm{ml} / \mathrm{min} / 1.73 \mathrm{~m}^{2}\right)$ 3 years after the AKI episode, with a correlation between reduction in GFR and the severity of the acute insult during hospitalization ${ }^{245}$. Notably, $16.6 \%$ of neonates with AKI in this cohort developed CKD (over the same follow-up period). In a separate cohort, $70 \%$ of children demonstrated indices of residual renal damage (namely, reduced GFR, proteinuria or hypertension) 6 months after the development of nephrotoxin-associated $\mathrm{AKI}^{242}$. The risk of developing adult CKD and end-stage renal disease (ESRD) following an episode of AKI was also highlighted by a 2012 meta-analysis ${ }^{246}$.

As mentioned above, evidence from small studies suggests that prematurity and IUGR are detrimental to nephrogenesis ${ }^{20,21,249,250}$; given the association between prematurity and IUGR with AKI, we propose that the abnormal nephrogenesis contributes to the increased risk of CKD in AKI survivors. Available evidence from studies of term and preterm infants in the NICU suggests that $31 \%$ (range 9-83\%) of neonatal AKI survivors will develop CKD (TABLE 3). Although these studies show that a considerable proportion of infants who develop AKI will also develop CKD, the attributable risk of AKI to $\mathrm{CKD}$ is unclear because AKI and CKD share many risk factors. Therefore, we do not yet know whether the development of CKD in a preterm infant who had AKI is simply due to impaired kidney development, the episode of AKI or a combination of the two ${ }^{251}$. Although an adequately powered prospective cohort study is needed to evaluate the relationship between AKI in critically ill neonates and CKD development in later life, it is likely that the kidneys of premature infants and neonates with extreme growth restriction at birth are primed for the development of CKD in childhood or adulthood. In some individuals, CKD might fully manifest only when the compensatory response of the kidney to decreased nephron mass is lost through the effects of an immunologic or non-immunologic insult that further reduces the already limited capacity of the remaining renal tissue (FIG. 3). This hypothesis suggests that the renal function of individuals born prematurely or with LBW, or who experienced an episode of AKI as an infant, should be carefully monitored for CKD throughout childhood and adult life.

Of note, not only neonatal AKI but also any kidney disease experienced in childhood that is apparently resolved can increase the risk of developing CKD in adult life. A nationwide study in Israel involving $>1.5$ million individuals found that a history of kidney disease in childhood, with no clinical or laboratory evidence of compromised GFR in adolescence, was associated with an increased risk of ESRD in later life compared with the risk of ESRD among those with no such history of kidney disease (HR 4.19, 95\% CI 3.52-4.99) ${ }^{252}$.

\section{Conclusions}

IUGR, preterm birth and LBW are increasingly recognized as key determinants of AKI in critically ill neonates and CKD sequelae in later life. Approaches to identify infants at risk of AKI and to establish measures to prevent the development of AKI are important given the association of AKI with prolonged length of hospital stay and increased mortality.

Although the true incidence of neonatal AKI remains ill-defined, the magnitude of preterm birth, with an approximate global incidence of $10 \%^{253,254}$, and of LBW, which affects $>22$ million infants globally each year ${ }^{255}$, combined with the potential harmful effects of these entities on the immature kidney, calls for urgent research and interventional approaches to limit the development of AKI - a life-threatening condition. Because maternal health, nutrition and lifestyle are important determinants of fetal outcomes, studies should focus on exploring whether maternal education and simple nutritional interventions can reduce the rate of LBW and prematurity and whether these interventions can reduce the incidence of AKI in newborn babies ${ }^{253,254}$. It also remains a priority to establish whether and to what extent AKI, severe prematurity and IUGR lead to CKD in childhood or young adulthood. Greater understanding of the relationships between these entities will aid in the development of cost-effective follow-up programmes over the life course of an individual with collaboration between neonatologists, paediatric nephrologists, paediatricians and adult nephrologists. Although validated guidelines are not available, recommendations for the follow-up of small for gestational age, preterm and LBW infants have recently been reported by the Low Birth and Nephron Number Working Group, a multidisciplinary working group that includes international expert obstetricians, neonatologists, paediatricians and nephrologists ${ }^{13,14}$, and in 2017 guidelines from the UK's National Institute for Health and Care Excellence (NICE) on the developmental follow-up of children and young adults who were born preterm ${ }^{256}$. Adherence to these recommendations is needed, as are approaches to increase awareness of possible consequences of low nephron endowment associated with prematurity and LBW on the postnatal risk of $\mathrm{AKI}$ and $\mathrm{CKD}$.

Published online 17 September 2018
1. Mehta, R. L. et al. International Society of Nephrology's 0by25 initiative for acute kidney injury (zero preventable deaths by 2025): a human rights case for nephrology. Lancet 385, 2616-2643 (2015).

2. Sharfuddin, A. A. $\&$ Molitoris, B. A. Pathophysiology of ischemic acute kidney injury. Nat. Rev. Nephrol. 7 , 189-200 (2011).

3. Zuk, A. \& Bonventre, J. V. Acute kidney injury. Annu. Rev. Med. 67, 293-307 (2016).

4. Lombardi, D., Becherucci, F. \& Romagnani, P. How much can the tubule regenerate and who does it?
An open question. Nephrol. Dial Transplant. 31, 1243-1250 (2016).

5. Lazzari, E. et al. Endocycle-related tubular cell hypertrophy and preogenitor proliferation recover renal function after acute kidney injury. Nat. Commun. 9, 1344 (2018).

6. Chawla L S. Eggers, P. W Star R. A \& Kimmel, P. L. Acute kidney injury and chronic kidney disease as interAcute kidney injury and chronic kidney disease as inter-
connected syndromes. N. Engl. J. Med. 371, 58-66 (2014). 7. Couser, W. G., Remuzzi, G., Mendis, S. ¿ Tonelli, M. The contribution of chronic kidney disease to the global burden of major noncommunicable diseases Kidney Int. 80, 1258-1270 (2011).

8. Gansevoort, R. T. et al. Chronic kidney disease and cardiovascular risk: epidemiology, mechanisms, and prevention. Lancet 382, 339-352 (2013).

9. GBD 2016 Causes of Death Collaborators. Global, regional, and national age-sex specific mortality for 264 causes of death, 1980-2016: a systematic analysis for the Global Burden of Disease Study 2016. Lancet 390, 1151-1210 (2017). 
10. Jha, V. et al. Chronic kidney disease: global dimension and perspectives. Lancet 382, 260-272 (2013).

11. Liyanage, T. et al. Worldwide access to treatment for end-stage kidney disease: a systematic review. Lancet 385, 1975-1982 (2015).

12. Luyckx, V. A. \& Brenner, B. M. Birth weight, malnutrition and kidney-associated outcomes - a global concern. Nat. Rev. Nephrol. 11, 135-149 (2015).

13. Luyckx, V. A. et al. A developmental approach to the prevention of hypertension and kidney disease: a report from the Low Birth Weight and Nephron Number Working Group. Lancet 390, 424-428 (2017).

14. Low Birth Weight and Nephron Number Working Group. The impact of kidney development on the life course: a consensus document for action. Nephron 136, 3-49 (2017).

15. Barker, D. J. The fetal and infant origins of disease. Eur. J. Clin. Invest. 25, 457-463 (1995).

16. Barker, D. J. \& Osmond, C. Infant mortality, childhood nutrition, and ischaemic heart disease in England and Wales. Lancet 1, 1077-1081 (1986).

17. Barker, D. J., Osmond C. \& Law, C. M The intrauterine and early postnatal origins of cardiovascular disease and chronic bronchitis. J. Epidemiol. Commun. Health. 43, 237-240 (1989).

18. Manalich, R., Reyes, L., Herrera, M., Melendi, C \& Fundora, I. Relationship between weight at birth and the number and size of renal glomeruli in humans: a histomorphometric study. Kidney Int. 58, 770-773 (2000).

19. Hinchliffe, S. A., Lynch, M. R., Sargent, P. H., Howard, C. V. $\&$ Van Velzen, D. The effect of intrauterine growth retardation on the development of renal nephrons. Br. J. Obstet. Gynaecol. 99, 296-301 (1992).

20. Rodriguez, M. M. et al. Histomorphometric analysis of postnatal glomerulogenesis in extremely preterm infants. Pediatr. Dev. Pathol. 7, 17-25 (2004).

21. Sutherland, M. R. et al. Accelerated maturation and abnormal morphology in the preterm neonatal kidney. J. Am. Soc. Nephrol. 22, 1365-1374 (2011)

22. Hughson, M. Farris, A. B. 3rd, Douglas-Denton, $\mathrm{R}$, Hoy, W. E. \& Bertram, J. F. Glomerular number and size in autopsy kidneys: the relationship to birth weight. Kidney Int. 63, 2113-2122 (2003).

23. Brenner, B. M., Garcia, D. L. \& Anderson, S. Glomeruli and blood pressure. Less of one, more the other? Am. J. Hypertens. 1, 335-347 (1988).

24. Askenazi, D. J., Griffin, R., McGwin, G., Carlo, W. \& Ambalavanan, N. Acute kidney injury is independently associated with mortality in very low birthweight infants: a matched case-control analysis. Pediatr. Nephrol. 24, 991-997 (2009).

25. Koralkar, R. et al. Acute kidney injury reduces survival in very low birth weight infants. Pediatr. Res. 69 , 354-358 (2011).

26. Viswanathan, S., Manyam, B., Azhibekov, T. \& Mhanna, M. J. Risk factors associated with acute kidney injury in extremely low birth weight (ELBW) infants. Pediatr. Nephrol. 27, 303-311 (2012).

27. Carmody, J. B., Swanson, J. R., Rhone, E. T. \& Charlton, J. R. Recognition and reporting of AKI in very low birth weight infants. Clin. J. Am. Soc. Nephrol. 9, 2036-2043 (2014).

28. Stojanovic, V., Barisic, N., Milanovic, B. \& Doronjski, A Acute kidney injury in preterm infants admitted to a neonatal intensive care unit. Pediatr. Nephrol. 29 2213-2220 (2014).

29. Nagaraj, N., Berwal, P. K., Srinivas, A. \& Berwal, A. A study of acute kidney injury in hospitalized preterm neonates in NICU. J. Neonatal Perinatal Med. 9, 417-421 (2016).

30. Daga, A., Dapaah-Siakwan, F, Rajbhandari, S Arevalo, C. \& Salvador, A. Diagnosis and risk factors of acute kidney injury in very low birth weight infants. Pediatr. Neonatol. 58, 258-263 (2017).

31. Selewski, D. T. et al. Neonatal acute kidney injury. Pediatrics 136, e463-e473 (2015)

32. Aydin, S. I. et al. Acute kidney injury after surgery for congenital heart disease. Ann. Thorac Surg. 94 1589-1595 (2012).

33. dos Santos El Halal, M. G. \& Carvalho, P. R. Acute kidney injury according to pediatric RIFLE criteria is associated with negative outcomes after heart surgery in children. Pediatr. Nephrol. 28 1307-1314 (2013).

34. Taylor, M. L. et al. Mild postoperative acute kidney injury and outcomes after surgery for congenital heart disease. J. Thorac Cardiovasc. Surg. 146, 146-152 (2013).

35. Wong, J. H. et al. Severe acute kidney injury following stage 1 norwood palliation: effect on outcomes and risk of severe acute kidney injury at subsequent surgical stages. Pediatr. Crit. Care Med. 17, 615-623 (2016).

36. Mathur, N. B., Agarwal, H. S. \& Maria, A. Acute renal failure in neonatal sepsis. Indian J. Pediatr. 73 499-502 (2006)

37. Sarkar, S. et al. Relationship between acute kidney injury and brain MRI findings in asphyxiated newborns after therapeutic hypothermia. Pediatr. Res. 75 431-435 (2014)

38. Askenazi, D. J. et al. Fluid overload and mortality are associated with acute kidney injury in sick near-term/ term neonate. Pediatr. Nephrol. 28, 661-666 (2013).

39. Selewski, D. T., Jordan, B. K., Askenazi, D. J. Dechert, R. E. \& Sarkar, S. Acute kidney injury in asphyxiated newborns treated with therapeutic hypothermia. J. Pediatr. 162, 725-729 e721 (2013).

40. Alaro, D., Bashir, A., Musoke, R. \& Wanaiana, L. Prevalence and outcomes of acute kidney injury in term neonates with perinatal asphyxia. Afr. Health Sci. 14, 682-688 (2014)

41. Askenazi, D. J et al. Acute kidney injury and renal replacement therapy independently predict mortality in neonatal and pediatric noncardiac patients on extracorporeal membrane oxygenation. Pediatr. Crit. Care Med. 12, e 1-6 (2011).

42. Gadepalli, S. K., Selewski, D. T., Drongowski, R. A. \& Mychaliska, G. B. Acute kidney injury in congenital diaphragmatic hernia requiring extracorporeal life support: an insidious problem. J. Pediatr. Surg. 46, 630-635 (2011)

43. Fleming, G. M. et al. The incidence of acute kidney injury and its effect on neonatal and pediatric extracorporeal membrane oxygenation outcomes: a multicenter report from the Kidney Intervention During Extracorporeal Membrane Oxygenation Study Group. Pediatr. Crit. Care Med. 17, 1157-1169 (2016).

44. Arcinue, R., Kantak, A. \& Elkhwad, M. Acute kidney injury in ELBW infants (<750 grams) and its associated risk factors. J. Neonatal Perinatal Med. 8, 349-357 (2015).

45. Csaicsich, D. et al. Renal failure, comorbidity and mortality in preterm infants. Wien Klin. Wochenschr. 120, 153-157 (2008).

46. Rhone, E. T., Carmody, J. B., Swanson, J. R. \& Charlton, J. R. Nephrotoxic medication exposure in very low birth weight infants. J. Matern. Fetal Neonatal Med. 27, 1485-1490 (2014).

47. Jetton, J. G. et al. Incidence and outcomes of neonatal acute kidney injury (AWAKEN): a multicentre, multinational, observational cohort study. Lancet Child Adolesc. Health 1, 184-194 (2017).

48. Askenazi, D. J., Ambalavanan, N. \& Goldstein, S. L. Acute kidney injury in critically ill newborns: what do we know? What do we need to learn? Pediatr Nephrol. 24, 265-274 (2009).

49. Gupta, C., Massaro, A. N. \& Ray, P. E. A new approach to define acute kidney injury in term newborns with hypoxic ischemic encephalopathy. Pediatr. Nephrol. 31, 1167-1178 (2016)

50. Jetton, J. G. \& Askenazi, D. J. Update on acute kidney injury in the neonate. Curr. Opin. Pediatr. 24 191-196 (2012)

51. Zappitelli, M. et al. Developing a neonatal acute kidney injury research definition: a report from the NIDDK neonatal AKI workshop. Pediatr. Res. 82, 569-573 (2017)

52. Kellum, J. A. \& Lameire, N. Diagnosis, evaluation, and management of acute kidney injury: a KDIGO summary (Part 1). Crit. Care. 17, 204 (2013)

53. Sarafidis, K. et al. Urine neutrophil gelatinaseassociated lipocalin to predict acute kidney injury in preterm neonates. A pilot study. Pediatr. Nephrol. 29 305-310 (2014)

54. Tabel, Y. et al. Urinary neutrophil gelatinaseassociated lipocalin as an early biomarker for prediction of acute kidney injury in preterm infants. Am. J. Perinatol. 31, 167-174 (2014).

55. Genc, G., Ozkaya, O., Avci, B., Aygun, C. \& Kucukoduk, S. Kidney injury molecule-1 as a promising biomarker for acute kidney injury in premature babies. Am. J. Perinatol. 30, 245-252 (2013).

56. Sarafidis, K. et al. Serum and urine acute kidney injury biomarkers in asphyxiated neonates. Pediatr. Nephrol. 27, 1575-1582 (2012)

57. Askenazi, D. J. et al. Urine biomarkers predict acute kidney injury in newborns. J. Pediatr. 161, 270-275 (2012).

58. Askenazi, D. J. et al. Urine biomarkers predict acute kidney injury and mortality in very low birth weight infants. J. Pediatr. 159, 907-912 (2011).

59. Askenazi, D. J. et al. Baseline values of candidate urine acute kidney injury biomarkers vary by gestational age in premature infants. Pediatr. Res. 70 302-306 (2011).

60. Hentschel, R., Lodige, B. \& Bulla, M. Rena insufficiency in the neonatal period. Clin. Nephrol. 46 54-58 (1996)

61. Drukker, A. \& Guignard, J. P. Renal aspects of the term and preterm infant: a selective update. Curr. Opin. Pediatr. 14, 175-182 (2002).

62. Cataldi, L. et al. Potential risk factors for the development of acute renal failure in preterm newborn infants: a case-control study. Arch. Dis. Child Fetal Neonatal Ed. 90, F514-F519 (2005).

63. Bezold, K. Y., Karjalainen, M. K., Hallman, M., Teramo, K \& Muglia, L. J. The genomics of preterm birth: from animal models to human studies. Genome Med. 5, 34 (2013).

64. Spitzer, A. Renal physiology and functional development. In Pediatric kidney disease. (ed. Edelmann, C. M.) 25-127 (Boston, Little \& Brown, 1978).

65. Gallini, F., Maggio, L., Romagnoli, C., Marrocco, G. \& Tortorolo, G. Progression of renal function in preterm neonates with gestational age $<$ or $=32$ weeks. Pediatr. Nephrol. 15, 119-124 (2000).

66. Finney, H., Newman, D. J., Thakkar, H., Fell, J. M. \& Price, C. P. Reference ranges for plasma cystatin $C$ and creatinine measurements in premature infants, neonates, and older children. Arch. Dis. Child. 82 71-75 (2000).

67. Lee, C. C. et al. Incidence and outcomes of acute kidney injury in extremely-low-birth-weight infants. PLOS ONE 12, e0187764 (2017).

68. Joseph, K. S., Liston, R. M., Dodds, L., Dahlgren, L. $\&$ Allen, A. C. Socioeconomic status and perinatal outcomes in a setting with universal access to essential health care services. CMAJ 177, 583-590 (2007).

69. Smith, L. K., Draper, E. S., Manktelow, B. N. Dorling, J. S. \& Field, D. J. Socioeconomic inequalities in very preterm birth rates. Arch. Dis. Child Fetal Neonatal Ed. 92, F11-F14 (2007).

70. Huynh, M., Parker, J. D., Harper, S., Pamuk, E. \& Schoendorf, K. C. Contextual effect of income inequality on birth outcomes. Int. J. Epidemiol. 34, 888-895 (2005)

71. Parker, J. D., Schoendorf, K. C. \& Kiely, J. L. Associations between measures of socioeconomic status and low birth weight, small for gestational age, and premature delivery in the United States. Ann. Epidemiol. 4, 271-278 (1994).

72. Gavin, A. R., Nurius, P. \& Logan-Greene, P. Mediators of adverse birth outcomes among socially disadvantaged women. J. Womens Health (Larchmt). 21, 634-642 (2012)

73. Fall, C. H. et al. Association between maternal age at childbirth and child and adult outcomes in the offspring: a prospective study in five low-income and middle-income countries (COHORTS collaboration). Lancet Glob. Health. 3, e366-377 (2015).

74. Stephenson, J. et al. Before the beginning: nutrition and lifestyle in the preconception period and its importance for future health. Lancet 391 1830-1841 (2018).

75. Han, Z., Mulla, S., Beyene, J., Liao, G. \& McDonald, S. D. Maternal underweight and the risk of preterm birth and low birth weight: a systematic review and meta-analyses. Int. J. Epidemiol. 40, 65-101 (2011)

76. Liu, P. et al. Association between perinatal outcomes and maternal pre-pregnancy body mass index. Obes. Rev. 17, 1091-1102 (2016).

77. Yu, Z. et al. Pre-pregnancy body mass index in relation to infant birth weight and offspring overweight obesity: a systematic review and meta-analysis. PLOS ONE 8, e61627 (2013).

78. Catalano, P. M. Obesity, insulin resistance, and pregnancy outcome. Reproduction 140, 365-371 (2010).

79. Piccoli, G. B. et al. Pregnancy and chronic kidney disease: a challenge in all CKD stages. Clin. J. Am. Soc. Nephrol. 5, 844-855 (2010).

80. Kendrick, J. et al. Kidney disease and maternal and fetal outcomes in pregnancy. Am. J. Kidney Dis. 66 55-59 (2015)

81. Piccoli, G. B. et al. Risk of adverse pregnancy outcomes in women with CKD. J. Am. Soc Nephrol. 26, 2011-2022 (2015)

82. Zhang, J. J. et al. A systematic review and metaanalysis of outcomes of pregnancy in CKD and CKD outcomes in pregnancy. Clin. J. Am. Soc. Nephrol. 10 1964-1978 (2015)

83. Khoury, J. C., Miodovnik, M., LeMasters, G. \& Sibai, B. Pregnancy outcome and progression of diabetic nephropathy. What's next? J. Matern. Fetal Neonatal Med. 11, 238-244 (2002). 
84. Klemetti, M. M. et al. Obstetric and perinatal outcome in type 1 diabetes patients with diabetic nephropathy during 1988-2011. Diabetologia 58, 678-686 (2015).

85. Phansenee, S., Sekararithi, R., Jatavan, P. \& Tongsong, T. Pregnancy outcomes among women with systemic lupus erythematosus: a retrospective cohort study from Thailand. Lupus 27, 158-164 (2018).

86. Skorpen, C. G. et al. Influence of disease activity and medications on offspring birth weight, pre-eclampsia and preterm birth in systemic lupus erythematosus: a population-based study. Ann. Rheum. Dis. 77 264-269 (2018)

87. Wallenius, M., Salvesen, K. A., Daltveit, A. K. \& Skomsvoll, J. F. Secular trends of pregnancies in women with inflammatory connective tissue disease. Acta Obstet. Gynecol. Scand. 94, 1195-1202 (2015).

88. Wagner, S. J. et al. Maternal and foetal outcomes in pregnant patients with active lupus nephritis. Lupus 18, 342-347 (2009)

89. Clowse, M. E., Magder, L. S., Witter, F. \& Petri, M. The impact of increased lupus activity on obstetric outcomes. Arthritis Rheum. 52, 514-521 (2005).

90. Clowse, M. E., Magder, L. S. \& Petri, M. The clinical utility of measuring complement and anti-dsDNA antibodies during pregnancy in patients with systemic lupus erythematosus. J. Rheumatol. 38, 1012-1016 (2011).

91. Savitz, D. A., Danilack, V. A., Engel, S. M., Elston, B. \& Lipkind, H. S. Descriptive epidemiology of chronic hypertension, gestational hypertension, and preeclampsia in New York State, 1995-2004. Matern. Child Health J. 18, 829-838 (2014).

92. Bramham, K. et al. Chronic hypertension and pregnancy outcomes: systematic review and meta-analysis. BMJ 348, g2301 (2014).

93. Conde-Agudelo, A., Rosas-Bermudez, A. \& Kafury-Goeta, A. C. Birth spacing and risk of advers perinatal outcomes: a meta-analysis. JAMA 295, 1809-1823 (2006)

94. Zhu, B. P., Rolfs, R. T., Nangle, B. E. \& Horan, J. M Effect of the interval between pregnancies on perinatal outcomes. N. Engl. J. Med. 340, 589-594 (1999).

95. Ball, S. J., Pereira, G., Jacoby, P., de Klerk, N. \& Stanley, F. J. Re-evaluation of link between interpregnancy interval and adverse birth outcomes: retrospective cohort study matching two intervals per mother. BMJ 349, g4333 (2014).

96. Sullivan, E. A. et al. International Committee for Monitoring Assisted Reproductive Technologies (ICMART) world report: assisted reproductive technology 2004. Hum. Reprod. 28, 1375-1390 (2013)

97. Mansour, R. et al. International Committee for Monitoring Assisted Reproductive Technologies world report: Assisted Reproductive Technology 2006. Hum. Reprod. 29, 1536-1551 (2014).

98. Luke, B. et al. Birth outcomes by infertility treatment: analyses of the population-based cohort: Massachusetts Outcomes Study of Assisted Reproductive Technologies (MOSART) J. Reprod. Med. 61, 114-127 (2016)

99. Grady, R., Alavi, N., Vale, R., Khandwala, M. \& McDonald, S. D. Elective single embryo transfer and perinatal outcomes: a systematic review and meta-analysis. Fertil. Steril. 97, 324-331 (2012).

100. Poikkeus, P., Gissler, M., Unkila-Kallio, L. Hyden-Granskog, C. \& Tiitinen, A. Obstetric and neonatal outcome after single embryo transfer. Hum. Reprod. 22, 1073-1079 (2007)

101. Kapiteijn, K. et al. Does subfertility explain the risk of poor perinatal outcome after IVF and ovarian hyperstimulation? Hum. Reprod. 21, 3228-3234 (2006).

102. Clausson, B., Lichtenstein, P. \& Cnattingius, S. Genetic influence on birthweight and gestational length determined by studies in offspring of twins. BJOC 107, 375-381 (2000)

103. York, T. P. et al. Fetal and maternal genes' influence on gestational age in a quantitative genetic analysis of 244,000 Swedish births. Am. J. Epidemiol. 178 543-550 (2013).

104. Plunkett, J. et al. Mother's genome or maternallyinherited genes acting in the fetus influence gestational age in familial preterm birth. Hum. Hered. 68, 209-219 (2009).

105. Kistka, Z. A. et al. Heritability of parturition timing: an extended twin design analysis. Am J. Obstet Gynecol. 199, 43.e1-43.e5 (2008)

106. Boyd, H. A. et al. Maternal contributions to preterm delivery. Am. J. Epidemiol. 170, 1358-1364 (2009).
107. Zhang, G. et al. Genetic associations with gestational duration and spontaneous preterm birth. N. Engl. J. Med. 377, 1156-1167 (2017)

108. Zhang, G. et al. Assessing the causal relationship of maternal height on birth size and gestational age at birth: a mendelian randomization analysis. PLOS Med. 12, e1001865 (2015).

109. Akbar, S. A. et al. Angiotensin II type 1 and 2 receptors gene polymorphisms in pre-eclampsia and normal pregnancy in three different populations. Acta Obstet. Gynecol. Scand. 88, 606-611 (2009).

110. Yamada, H., Sata, F., Saijo, Y., Kishi, R. \& Minakami, H. Genetic factors in fetal growth restriction and miscarriage. Semin. Thromb. Hemost. 31, 334-345 (2005).

111. Edwards, D. R. et al. Polymorphisms in maternal and fetal genes encoding for proteins involved in extracellular matrix metabolism alter the risk for small-for-gestational-age. J. Matern. Fetal Neonatal Med. 24, 362-380 (2011).

112. Chelbi, S. T. et al. Genetic and epigenetic mechanisms collaborate to control SERPINA3 expression and its association with placental diseases. Hum. Mol. Genet. 21, 1968-1978 (2012)

113. McMillen, I. C. \& Robinson, J. S. Developmental origins of the metabolic syndrome: prediction, plasticity, and programming. Physiol. Rev. 85, 571-633 (2005)

114. Pinney, S. E., Jaeckle Santos, L. J., Han, Y., Stoffers, D. A ¿ Simmons, R. A. Exendin-4 increases histone acetylase activity and reverses epigenetic modifications that silence $\mathrm{Pdx} 1$ in the intrauterine growth retarded rat. Diabetologia 54, 2606-2614 (2011).

115. Sohi, G., Marchand, K., Revesz, A., Arany, E. \& Hardy, D. B. Maternal protein restriction elevates cholesterol in adult rat offspring due to repressive changes in histone modifications at the cholesterol 7alpha-hydroxylase promoter. Mol. Endocrinol. 25 785-798 (2011)

116. Koukoura, O. et al. Loss of imprinting and aberrant methylation of IGF2 in placentas from pregnancies complicated with fetal growth restriction. Int. J. Mol. Med. 28, 481-487 (2011).

117. Koukoura, O. et al. Hypomethylation along with increased $\mathrm{H} 19$ expression in placentas from pregnancies complicated with fetal growth restriction. Placenta 32, 51-57 (2011).

118. Lambertini, L. et al. Differential methylation of imprinted genes in growth-restricted placentas. Reprod. Sci. 18, 1111-1117 (2011)

119. Banister, C. E. et al. Infant growth restriction is associated with distinct patterns of DNA methylation in human placentas. Epigenetics 6, 920-927 (2011).

120. Mouillet, J. F. et al. The levels of hypoxia-regulated microRNAs in plasma of pregnant women with fetal growth restriction. Placenta 31, 781-784 (2010).

121. Hromadnikova, I., Kotlabova, K., Doucha, J., Dlouha, K $\S$ Krofta, L. Absolute and relative quantification of placenta-specific microRNAs in maternal circulation with placental insufficiency-related complications. J. Mol. Diagn. 14, 160-167 (2012).

122. Tobi, E. W. et al. DNA methylation signatures link prenatal famine exposure to growth and metabolism. Nat. Commun. 5, 5592 (2014)

123. Wang, P. X., Wang, J. J., Lei, Y. X., Xiao, L. \& Luo, Z C. Impact of fetal and infant exposure to the Chinese Great Famine on the risk of hypertension in adulthood. PLOS ONE 7, e49720 (2012).

124. Radford, E. J. et al. In utero effects. In utero undernourishment perturbs the adult sperm methylome and intergenerational metabolism. Science 345, 1255903 (2014).

125. Radford, E. J. Exploring the extent and scope of epigenetic inheritance. Nat. Rev. Endocrinol. 14, 345-355 (2018)

126. Rasmussen, K., Yaktine, A L (eds). Weight Gain During Pregnancy: Reexamining the Guidelines (National Academies Press, 2009).

127. Goldstein, R. F. et al. Association of gestational weight gain with maternal and infant outcomes: a systematic review and meta-analysis. JAMA 317, 2207-2225 (2017).

128. Vehaskari, V. M., Aviles, D. H. \& Manning, J. Prenatal programming of adult hypertension in the rat. Kidney Int. 59, 238-245 (2001)

129. Moore, V. M., Davies, M. J., Willson, K. J., Worsley, A. \& Robinson, J. S. Dietary composition of pregnant women is related to size of the baby at birth. J. Nutr. 134, 1820-1826 (2004)

130. Cuco, G. et al. Association of maternal protein intake before conception and throughout pregnancy with birth weight. Acta Obstet. Gynecol. Scand. 85 413-421 (2006)

131. Olsen, S. F. et al. Milk consumption during pregnancy is associated with increased infant size at birth prospective cohort study. Am. J. Clin. Nutr. $\mathbf{8 6}$ 1104-1110 (2007)

132. Mathews, F., Yudkin, P. \& Neil, A. Influence of maternal nutrition on outcome of pregnancy: prospective cohort study. BMJ 319, 339-343 (1999).

133. Chong, M. F. et al. Maternal protein intake during pregnancy is not associated with offspring birth weight in a multiethnic Asian population. J. Nutr. 145 1303-1310 (2015).

134. Patra, J. et al. Dose-response relationship between alcohol consumption before and during pregnancy and the risks of low birthweight, preterm birth and small for gestational age (SGA)-a systematic review and meta-analyses. BJOG 118, 1411-1421 (2011).

135. Strandberg-Larsen, K. et al. Association of lightto-moderate alcohol drinking in pregnancy with preterm birth and birth weight: elucidating bias by pooling data from nine European cohorts. Eur. J. Epidemiol. 32, 751-764 (2017).

136. O'Leary, C. M. \& Bower, C. Guidelines for pregnancy: what's an acceptable risk, and how is the evidence (finally) shaping up? Drug Alcohol Rev. 31, 170-183 (2012).

137. Henderson, J., Gray, R. \& Brocklehurst, P. Systematic review of effects of low-moderate prenatal alcoho exposure on pregnancy outcome. BJOG 114 243-252 (2007)

138. Lundsberg, L. S., Illuzzi, J. L., Belanger, K., Triche, E. W. \& Bracken, M. B. Low-to-moderate prenatal alcohol consumption and the risk of selected birth outcomes: a prospective cohort study. Ann. Epidemiol. 25, 46-54 e3 (2015).

139. Ko, T. J. et al. Parental smoking during pregnancy and its association with low birth weight, small for gestational age, and preterm birth offspring: a birth cohort study. Pediatr. Neonatol. 55, 20-27 (2014)

140. Jaddoe, V. W. et al. Active and passive materna smoking during pregnancy and the risks of low birthweight and preterm birth: the Generation R Study. Paediatr. Perinat. Epidemiol. 22, 162-171 (2008).

141. Agrawal, A. et al. The effects of maternal smoking during pregnancy on offspring outcomes. Prev. Med. 50, 13-18 (2010).

142. Jauniaux, E. \& Burton, G. J. Morphological and biological effects of maternal exposure to tobacco smoke on the feto-placental unit. Early Hum. Dev. 83 699-706 (2007)

143. Kupers, L. K. et al. DNA methylation mediates the effect of maternal smoking during pregnancy on birthweight of the offspring. Int. J. Epidemiol. 44 , 1224-1237 (2015).

144. Bouwland-Both, M. I. et al. Prenatal parental tobacco smoking, gene specific DNA methylation, and newborns size: the Generation R study. Clin. Epigenet. 7, 83 (2015)

145. Janssen, B. G. et al. Placental mitochondrial DNA and CYP1A1 gene methylation as molecular signatures for tobacco smoke exposure in pregnant women and the relevance for birth weight. J. Transl. Med. 15, 5 (2017).

146. Guron, G. \& Friberg, P. An intact renin-angiotensin system is a prerequisite for normal renal development. J. Hypertens. 18, 123-137 (2000).

147. Friberg. P. et al. Renin-angiotensin system in neonatal rats: induction of a renal abnormality in response to ACE inhibition or angiotensin II antagonism Kidney Int. 45, 485-492 (1994).

148. Shotan, A., Widerhorn, J., Hurst, A. \& Elkayam, U. Risks of angiotensin-converting enzyme inhibition during pregnancy: experimental and clinical evidence, potential mechanisms, and recommendations for use. Am. J. Med. 96, 451-456 (1994).

149. Zambraski, E. J. The effects of nonsteroidal antiinflammatory drugs on renal function: experimental studies in animals. Semin. Nephrol. 15, 205-213 (1995).

150. van der Heijden, B. \& Gubler, M. C. Renal failure in the neonate associated with in utero exposure to nonsteroidal anti-inflammatory agents. Pediatr. Nephrol. 9, 675 (1995)

151. Alano, M. A., Ngougmna, E., Ostrea, E. M. Jr \& Konduri, G. G. Analysis of nonsteroidal antiinflammatory drugs in meconium and its relation to persistent pulmonary hypertension of the newborn. Pediatrics 107, 519-523 (2001).

152. Cuzzolin, L. et al. Postnatal renal function in preterm newborns: a role of diseases, drugs and therapeutic interventions. Pediatr. Nephrol. 21, 931-938 (2006). 
153. Mol, B. W. J. et al. Pre-eclampsia. Lancet 387 , 999-1011 (2016)

154. Bilano, V. L., Ota, E., Ganchimeg, T., Mori, R. \& Souza, J. P. Risk factors of pre-eclampsia/eclampsia and its adverse outcomes in low- and middle-income countries: a WHO secondary analysis. PLOS ONE 9, e91198 (2014)

155. Sherf, Y. et al. Like mother like daughter: low birth weight and preeclampsia tend to reoccur at the nex generation. J. Matern. Fetal Neonatal Med. 7, 1-7 (2017)

156. Abitbol, C. L., DeFreitas, M. J. \& Strauss, J. Assessment of kidney function in preterm infants: lifelong implications. Pediatr. Nephrol. 31 , 2213-2222 (2016)

157. Nada, A., Bonachea, E. M. \& Askenazi, D. J. Acute kidney injury in the fetus and neonate. Semin. Fetal Neonatal Med. 22, 90-97 (2017).

158. Kaur, S. et al. Evaluation of glomerular and tubular renal function in neonates with birth asphyxia. Ann. Trop. Paediatr. 31, 129-134 (2011).

159. Blinder, J. J. et al. Congenital heart surgery in infants: effects of acute kidney injury on outcomes. J. Thorac. Cardiovasc. Surg. 143, 368-374 (2012).

160. Krawczeski, C. D. et al. Neutrophil gelatinaseassociated lipocalin concentrations predict development of acute kidney injury in neonates and children after cardiopulmonary bypass. J. Pediatr. 158, 1009-1015 (2011).

161. Morgan, C. J. et al. Risk factors for and outcomes of acute kidney injury in neonates undergoing complex cardiac surgery. J. Pediatr. 162, 120-127 (2013).

162. Stoll, B. J. et al. Early onset neonatal sepsis the burden of group B Streptococcal and E. coli disease continues. Pediatrics 127, 817-826 (2011)

163. Shane, A. L., Sanchez, P. J. \& Stoll, B. J. Neonatal sepsis. Lancet 390, 1770-1780 (2017).

164. Palmeira, P., Quinello, C., Silveira-Lessa, A. L. Zago, C. A. \& Carneiro-Sampaio, M. IgG placental transfer in healthy and pathological pregnancies. Clin. Dev. Immunol. 2012, 985646 (2012).

165. Momtaz, H. E. Sabzehei, M. K., Rasuli, B. \& Torabian, S. The main etiologies of acute kidney injury in the newborns hospitalized in the neonatal intensive care unit. J. Clin. Neonatol. 3, 99-102 (2014).

166. Vachvanichsanong, P. et al. Neonatal acute kidney injury in a tertiary center in a developing country. Nephrol. Dial Transplant. 27, 973-977 (2012).

167. Bolat, F. et al. Acute kidney injury in a single neonatal intensive care unit in Turkey. World J. Pediatr. 9 323-329 (2013)

168. Blatt, N. B., Srinivasan, S., Mottes, T., Shanley, M. M. $\&$ Shanley, T. P. Biology of sepsis: its relevance to pediatric nephrology. Pediatr. Nephrol. 29 2273-2287 (2014)

169. Sakr, Y., Dubois, M. J., De Backer, D., Creteur, J. \& Vincent, J. L. Persistent microcirculatory alterations are associated with organ failure and death in patients with septic shock. Crit. Care Med. 32, 1825-1831 (2004).

170. Vincent, J. L. \& De Backer, D. Microvascular dysfunction as a cause of organ dysfunction in severe sepsis. Crit. Care 9 (Suppl. 4), S9-S12 (2005).

171. Venkatachalam, M. A. \& Weinberg, J. M. The tubule pathology of septic acute kidney injury: a neglected area of research comes of age. Kidney Int. $\mathbf{8 1}$ 338-340 (2012).

172. Suzuki, M. Children's toxicology from bench to bed drug-induced renal injury (4): effects of nephrotoxic compounds on fetal and developing kidney. J. Toxicol. Sci. 34 (Suppl. 2), SP267-SP271 (2009).

173. Gilbert, T., Lelievre-Pegorier, M., Malienou, R. Meulemans, A. \& Merlet-Benichou, C. Effects of prenatal and postnatal exposure to gentamicin on renal differentiation in the rat. Toxicology 43 301-313 (1987)

174. Laughon, M. M. et al. Drug labeling and exposure in neonates JAMA Pediatr 168, 130-136 (2014).

175. Kent, A., Turner, M. A., Sharland, M. \& Heath, P. T. Aminoglycoside toxicity in neonates: something to worry about? Expert Rev. Anti Infect. Ther. 12, 319-331 (2014).

176. Zappitelli, M., Selewski, D. T \& Askenazi, D. J. Nephrotoxic medication rxposure and acute kidney injury in neonates. NeoReviews 13, e420-e427 (2012).

177. Oktem, F. et al. In vivo evidences suggesting the role of oxidative stress in pathogenesis of vancomycininduced nephrotoxicity: protection by erdosteine. Toxicology 215, 227-233 (2005).

178. Lopez-Novoa, J. M., Quiros, Y., Vicente, L., Morales, A. I. \& Lopez-Hernandez, F. J. New insights into the mechanism of aminoglycoside nephrotoxicity: an integrative point of view. Kidney Int. 79, 33-45 (2011).

179. Allegaert, K., Cossey, V. \& van den Anker, J. N. Dosing guidelines of aminoglycosides in neonates: a balance between physiology and feasibility. Curr. Pharm. Des. 21, 5699-5704 (2015)

180. Fanos, V., Cuzzolin, L., Atzei, A. \& Testa, M. Antibiotics and antifungals in neonatal intensive care units: a review. J. Chemother. 19, 5-20 (2007).

181. Hamill, R. J. Amphotericin B formulations: a comparative review of efficacy and toxicity. Drugs 73, 919-934 (2013)

182. Zager, R. A., Bredl, C. R. \& Schimpf, B. A. Direct amphotericin B-mediated tubular toxicity: assessments of selected cytoprotective agents. Kidney Int. 41, 1588-1594 (1992).

183. Branch, R. A. Prevention of amphotericin B-induced renal impairment. A review on the use of sodium supplementation. Arch. Intern. Med. 148 2389-2394 (1988).

184. Turkova, A., Roilides, E. \& Sharland, M. Amphotericin $B$ in neonates: deoxycholate or lipid formulation as first-line therapy - is there a 'right' choice? Curr. Opin. Infect. Dis. 24, 163-171 (2011).

185. Manzoni, P. et al. Liposomal amphotericin B does not induce nephrotoxicity or renal function impairment in premature neonates. Early Hum. Dev. 88 (Suppl. 2), S86-S91 (2012).

186. Karadag-Oncel, E., Ozsurekci, Y., Yurdakok, M. \& Kara, A. Is liposomal amphotericin B really safety in neonates? Early Hum. Dev. 89, 35-36 (2013).

187. Scarcella, A., Pasquariello, M. B., Giugliano, B., Vendemmia, M. \& de Lucia, A. Liposomal amphotericin $B$ treatment for neonatal fungal infections. Pediatr. Infect. Dis. J. 17, 146-148 (1998)

188. Heyman, S. N., Khamaisi, M., Rosen, S. \& Rosenberger, C. Renal parenchymal hypoxia, hypoxia response and the progression of chronic kidney disease. Am. J. Nephrol. 28, 998-1006 (2008).

189. Cetin, I., Mando, C. \& Calabrese, S. Maternal predictors of intrauterine growth restriction. Curr. Opin. Clin. Nutr. Metab. Care 16, 310-319 (2013).

190. Koullali, B., Oudijk, M. A., Nijman, T. A., Mol, B. W. \& Pajkrt, E. Risk assessment and management to prevent preterm birth. Semin. Fetal Neonatal Med. 21, 80-88 (2016).

191. Fleming, T. P. et al. Origins of lifetime health around the time of conception: causes and consequences. Lancet 391, 1842-1852 (2018)

192. Sebert, S., Sharkey, D., Budge, H. \& Symonds, M. E. The early programming of metabolic health: is epigenetic setting the missing link? Am. J. Clin. Nutr 94, 1953S-1958S (2011)

193. Wang, J. et al. Nutrition, epigenetics, and metabolic syndrome. Antioxid. Redox Signal. 17, 282-301 (2012).

194. Kessler, N. J., Waterland, R. A

Andrew Prentice, M. A. M., \& Silver, M. J. Establishment of environmentally sensitive DNA methylation states in the very early human embryo. Sci. Adv. 4, eaat2624 (2018).

195. Anderson, O. S., Sant, K. E. \& Dolinoy, D. C. Nutrition and epigenetics: an interplay of dietary methyl donors one-carbon metabolism and DNA methylation. J. Nutr. Biochem. 23, 853-859 (2012).

196. Sundrani, D. P., Chavan Gautam, P. M., Mehendale, S. S. \& Joshi, S. R. Altered metabolism of maternal micronutrients and omega 3 fatty acids epigenetically regulate matrix metalloproteinases in preterm pregnancy: a novel hypothesis. Med. Hypotheses 77. 878-883 (2011)

197. Jiang, X. et al. Maternal choline intake alters the epigenetic state of fetal cortisol-regulating genes in humans. FASEB J. 26, 3563-3574 (2012).

198. Zeng, Y., Gu, P., Liu, K. \& Huang, P. Maternal protein restriction in rats leads to reduced PGC- 1 alpha expression via altered DNA methylation in skeletal muscle. Mol. Med. Rep. 7, 306-312 (2013).

199. Watkins, A. J. et al. Low protein diet fed exclusively during mouse oocyte maturation leads to behavioural and cardiovascular abnormalities in offspring. J. Physiol. 586, 2231-2244 (2008).

200. Kwong, W. Y., Wild, A. E., Roberts, P., Willis, A. C. \& Fleming, T. P. Maternal undernutrition during the preimplantation period of rat development causes blastocyst abnormalities and programming of postnatal hypertension. Development 127, 4195-4202 (2000).

201. Watkins, A. J. et al. Adaptive responses by mouse early embryos to maternal diet protect fetal growth but predispose to adult onset disease. Biol. Reprod. 78, 299-306 (2008).
202. Eckert, J. J. et al. Metabolic induction and early responses of mouse blastocyst developmental programming following maternal low protein diet affecting life-long health. PLOS ONE 7, e52791 (2012)

203. Sun, C. et al. Mouse early extra-embryonic lineages activate compensatory endocytosis in response to poor maternal nutrition. Development 141 1140-1150 (2014).

204. Denisenko, O. et al. Regulation of ribosomal RNA expression across the lifespan is fine-tuned by maternal diet before implantation. Biochim. Biophys. Acta 1859, 906-913 (2016).

205. Watkins, A. J. et al. Maternal nutrition modifies trophoblast giant cell phenotype and fetal growth in mice. Reproduction 149, 563-575 (2015).

206. Waterland, R. A. et al. Season of conception in rural gambia affects DNA methylation at putative human metastable epialleles. PLoS Genet. 6, e1001252 (2010).

207. Dominguez-Salas, P. et al. Maternal nutrition at conception modulates DNA methylation of human metastable epialleles. Nat. Commun. 5, 3746 (2014).

208. Lillycrop, K. A., Phillips, E. S., Jackson, A. A. Hanson, M. A. \& Burdge, G. C. Dietary protein restriction of pregnant rats induces and folic acid supplementation prevents epigenetic modification of hepatic gene expression in the offspring. J. Nutr. 135 , 1382-1386 (2005)

209. Lillycrop, K. A. et al. Induction of altered epigenetic regulation of the hepatic glucocorticoid receptor in the offspring of rats fed a protein-restricted diet during pregnancy suggests that reduced DNA methyltransferase- 1 expression is involved in impaired DNA methylation and changes in histone modifications. Br. J. Nutr. 97, 1064-1073 (2007).

210. Haider, B. A. \& Bhutta, Z. A. Multiple-micronutrient supplementation for women during pregnancy. Cochrane Database Syst. Rev, 4, CD004905 (2015).

211. da Silva Lopes, K. et al. Effects of nutrition interventions during pregnancy on low birth weight: an overview of systematic reviews. BMJ Glob. Health 2, e000389 (2017).

212. Fryer, A. A et al. Quantitative, high-resolution epigenetic profiling of $\mathrm{CpG}$ loci identifies associations with cord blood plasma homocysteine and birth weight in humans. Epigenetics 6, 86-94 (2011).

213. Karlowicz, M. G. \& Adelman, R. D. Nonoliguric and oliguric acute renal failure in asphyxiated term neonates. Pediatr. Nephrol. 9, 718-722 (1995).

214. Arikan, A. A. et al. Fluid overload is associated with impaired oxygenation and morbidity in critically ill children. Pediatr. Crit. Care Med. 13, 253-258 (2012).

215. Wilder, N. S., Yu, S., Donohue, J. E., Goldberg, C. S. \& Blatt, N. B. Fluid overload is associated with late poor outcomes in neonates following cardiac surgery. Pediatr. Crit. Care Med. 17, 420-427 (2016).

216. Koyner, J. L. et al. Furosemide stress test and biomarkers for the prediction of AKI severity. J. Am. Soc. Nephrol. 26, 2023-2031 (2015).

217. Chawla, L. S. et al. Development and standardization of a furosemide stress test to predict the severity of acute kidney injury. Crit. Care. 17, R207 (2013).

218. Merheb, R. C., Kruzer, K. A. \& Mhanna, M. J. The effect of bumetanide in extremely low birth weight infants with acute kidney injury during their first weeks of life. J. Clin. Pediatr. Nephrol. 2, 53-63 (2014).

219. Oliveros, M., Pham, J. T., John, E., Resheidat, A. \& Bhat, R. The use of bumetanide for oliguric acute renal failure in preterm infants. Pediatr. Crit. Care Med. 12 210-214 (2011)

220. Eslami, Z., Shajari, A., Kheirandish, M. \& Heidary, A. Theophylline for prevention of kidney dysfunction in neonates with severe asphyxia. Iran. J. Kidney Dis. 3 222-226 (2009).

221. Cattarelli, D et al. A randomised, double blind, placebo controlled trial of the effect of theophylline in prevention of vasomotor nephropathy in very preterm neonates with respiratory distress syndrome. Arch. Dis. Child Fetal Neonatal Ed. 91, F80-F84 (2006).

222. Bakr, A. F. Prophylactic theophylline to prevent renal dysfunction in newborns exposed to perinatal asphyxia - a study in a developing country. Pediatr. Nephrol. 20, 1249-1252 (2005).

223. Jenik, A. G. et al. A randomized, double-blind, placebo-controlled trial of the effects of prophylactic theophylline on renal function in term neonates with perinatal asphyxia. Pediatrics 105, E45 (2000).

224. Al-Wassia, H., Alshaikh, B. \& Sauve, R. Prophylactic theophylline for the prevention of severe renal dysfunction in term and post-term neonates with perinatal asphyxia: a systematic review and metaanalysis of randomized controlled trials. J. Perinatol. 33, 271-277 (2013) 
225. Ferguson, K. N., Roberts, C. T., Manley, B. J. \& Davis, P. G. Interventions to improve rates of successful extubation in preterm infants: a systematic review and meta-analysis. JAMA Pediatr. 171 165-174 (2017)

226. Harer, M. W. et al. Association between early caffeine citrate administration and risk of acute kidney injury in preterm neonates: results from the AWAKEN study. JAMA Pediatr. 172, e 180322 (2018).

227. Ricci, Z. et al. Fenoldopam in newborn patients undergoing cardiopulmonary bypass: controlled clinical trial. Interact. Cardiovasc. Thorac. Surg. 7 , 1049-1053 (2008)

228. Ricci, Z. et al. High-dose fenoldopam reduces postoperative neutrophil gelatinase-associated lipocaline and cystatin C levels in pediatric cardiac surgery. Crit. Care 15, R160 (2011).

229. Matzke, G. R. et al. Drug dosing consideration in patients with acute and chronic kidney disease-a clinical update from Kidney Disease: Improving Global Outcomes (KDICO). Kidney Int. 80, 1122-1137 (2011).

230. Goldstein, S. L. et al. A sustained quality improvement program reduces nephrotoxic medication-associated acute kidney injury. Kidney Int. 90, 212-221 (2016).

231. Sutherland, S. M. et al. Fluid overload and mortality in children receiving continuous renal replacement therapy: the prospective pediatric continuous renal replacement therapy registry. Am. J. Kidney Dis. $\mathbf{5 5}$ 316-325 (2010).

232. Ronco, C., Garzotto, F. \& Ricci, Z. CA.R.PE.DI.E.M (Cardio-Renal Pediatric Dialysis Emergency Machine): evolution of continuous renal replacement therapies in infants. A personal journey. Pediatr. Nephrol. 27, 1203-1211 (2012).

233. Ronco, C. et al. Continuous renal replacement therapy in neonates and small infants: development and first-in-human use of a miniaturised machine (CARPEDIEM). Lancet 383, 1807-1813 (2014).

234. Hothi, D. K. Designing technology to meet the therapeutic demands of acute renal injury in neonates and small infants. Pediatr. Nephrol. 29, 1869-1871 (2014).

235. Harshman, L. A. et al. Peritoneal dialysis in an extremely low-birth-weight infant with acute kidney injury. Clin. Kidney J. 7, 582-585 (2014).

236. Alparslan, C. et al. The performance of acute peritoneal dialysis treatment in neonatal period Ren. Fail. 34, 1015-1020 (2012).
237. Unal, S. et al. The implementation of neonatal peritoneal dialysis in a clinical setting. J. Matern. Fetal Neonatal Med. 25, 2111-2114 (2012).

238. Oyachi, N. et al. Use of a flexible Blake(R) silicone drains for peritoneal dialysis in the neonatal intensive care unit. Pediatr. Int 53, 417-418 (2011).

239. Yu, J. E., Park, M. S. \& Pai, K. S. Acute peritoneal dialysis in very low birth weight neonates using a vascular catheter. Pediatr. Nephrol. 25, 367-371 (2010).

240. Andreoli, S. P. Acute renal failure in the newborn Semin. Perinatol. 28, 112-123 (2004).

241. Agras, P. I. et al. Acute renal failure in the neonatal period. Ren. Fail. 26, 305-309 (2004)

242. Abitbol, C. L. et al. Long-term follow-up of extremely low birth weight infants with neonatal renal failure. Pediatr. Nephrol. 18, 887-893 (2003).

243. Basile, D. P. The endothelial cell in ischemic acute kidney injury: implications for acute and chronic function. Kidney Int. 72, 151-156 (2007).

244. Askenazi, D. J., Feig, D. I., Graham, N. M., Hui-Stickle, S. \& Goldstein, S. L. 3-5 year longitudinal follow-up of pediatric patients after acute renal failure. Kidney Int. 69, 184-189 (2006)

245. Mammen, C. et al. Long-term risk of CKD in children surviving episodes of acute kidney injury in the intensive care unit: a prospective cohort study. Am. J. Kidney Dis. 59, 523-530 (2012).

246. Coca, S. G., Singanamala, S. \& Parikh, C. R. Chronic kidney disease after acute kidney injury: a systematic review and meta-analysis. Kidney Int. 81, 442-448 (2012).

247. Abdulkader, R. C., Liborio, A. B. \& Malheiros, D. M. Histological features of acute tubular necrosis in native kidneys and long-term renal function. Ren. Fail. 30, 667-673 (2008)

248. Basile, D. P. Rarefaction of peritubular capillaries following ischemic acute renal failure: a potential factor predisposing to progressive nephropathy. Curr. Opin. Nephrol. Hypertens. 13, 1-7 (2004).

249. Faa, G. et al. Marked interindividual variability in rena maturation of preterm infants: lessons from autopsy. J. Matern. Fetal Neonatal Med. 23 (Suppl. 3), 129-133 (2010)

250. Carmody, J. B. \& Charlton, J. R. Short-term gestation, long-term risk: prematurity and chronic kidney disease. Pediatrics 131, 1168-1179 (2013).

251. Harer, M. W., Pope, C. F., Conaway, M. R. \& Charlton, J. R. Follow-up of Acute kidney injury in Neonates during Childhood Years (FANCY) a prospective cohort study. Pediatr. Nephrol. 32 , 1067-1076 (2017).

252. Calderon-Margalit, R. et al. History of childhood kidney disease and risk of adult end-stage renal disease. N. Engl. J. Med. 378, 428-438 (2018)

253. Chang, H. H. et al. Preventing preterm births: analysis of trends and potential reductions with interventions in 39 countries with very high human development index. Lancet 381, 223-234 (2013).

254. Lee, A. C. et al. National and regional estimates of term and preterm babies born small for gestational age in 138 low-income and middle-income countries in 2010. Lancet Glob. Health 1, e26-e36 (2013).

255. UNICEF. Undernourishment in the womb can lead to diminished potential and predispose infants to early death. UNICEF low birthweight, https:// data.unicef.org/topic/nutrition/low-birthweight/ (2014).

256. Kallioinen, M., Eadon, H., Murphy, M. S. \& Baird, G. Developmental follow-up of children and young people born preterm: summary of NICE guidance. BMJ 358, j3514 (2017).

257. Polito, C., Papale, M. R. \& La Manna, A. Long-term prognosis of acute renal failure in the full-term neonate. Clin. Pediatr. (Phila.) 37, 381-385 (1998)

258. Zwiers, A. J. et al. CKD and hypertension during long-term follow-up in children and adolescents previously treated with extracorporeal membrane oxygenation. Clin. J. Am. Soc. Nephrol. 9, 2070-2078 (2014).

259. Cooper, D. S. et al. Follow-Up Renal Assessment of Injury Long-Term After Acute Kidney Injury (FRAIL-AKI). Clin. J. Am. Soc. Nephrol. 11, 21-29 (2016).

260. Bruel, A. et al. Renal outcome in children born preterm with neonatal acute renal failure: IRENEO-a prospective controlled study. Pediatr. Nephrol. 31 , 2365-2373 (2016).

\section{Author contributions}

N.P. and M.C. researched data for the article. N.P. and G.R. discussed how to organize the manuscript and which topics to cover. N.P. and M.C. wrote the first draft of the manuscript, which was reviewed, implemented and edited by D.A. and G.R. before submission.

Competing interests

The authors declare no competing interests.

Publisher's note

Springer Nature remains neutral with regard to jurisdictional claims in published maps and institutional affiliations. 